\title{
Treatment Readiness in a Sample of Antisocial Youth: Assessing Characteristics for Use in Decision-Making
}

\author{
Sylvie Lalonde
}

A thesis submitted to the Faculty of Graduate Studies and Research in partial fulfillment of the requirements of the Master of Arts degree

\author{
Department of Psychology \\ Carleton University \\ Ottawa, ON
}

March 2007

(C) 2007 Sylvie Lalonde 


$\begin{array}{ll}\begin{array}{l}\text { Library and } \\ \text { Archives Canada }\end{array} & \begin{array}{l}\text { Bibliothèque et } \\ \text { Archives Canada }\end{array} \\ \begin{array}{l}\text { Published Heritage } \\ \text { Branch }\end{array} & \begin{array}{l}\text { Direction du } \\ \text { Patrimoine de l'édition }\end{array} \\ \begin{array}{l}\text { 395 Wellington Street } \\ \text { Ottawa ON K1A ON4 } \\ \text { Canada }\end{array} & \begin{array}{l}\text { 395, rue Wellington } \\ \text { Ottawa ON K1A 0N4 } \\ \text { Canada }\end{array}\end{array}$

Your file Votre référence ISBN: 978-0-494-26954-1 Ourfile Notre référence ISBN: 978-0-494-26954-1

NOTICE:

The author has granted a nonexclusive license allowing Library and Archives Canada to reproduce, publish, archive, preserve, conserve, communicate to the public by telecommunication or on the Internet, loan, distribute and sell theses worldwide, for commercial or noncommercial purposes, in microform, paper, electronic and/or any other formats.

The author retains copyright ownership and moral rights in this thesis. Neither the thesis nor substantial extracts from it may be printed or otherwise reproduced without the author's permission.
AVIS:

L'auteur a accordé une licence non exclusive permettant à la Bibliothèque et Archives Canada de reproduire, publier, archiver, sauvegarder, conserver, transmettre au public par télécommunication ou par l'Internet, prêter, distribuer et vendre des thèses partout dans le monde, à des fins commerciales ou autres, sur support microforme, papier, électronique et/ou autres formats.

L'auteur conserve la propriété du droit d'auteur et des droits moraux qui protège cette thèse. $\mathrm{Ni}$ la thèse ni des extraits substantiels de celle-ci ne doivent être imprimés ou autrement reproduits sans son autorisation.
In compliance with the Canadian

Privacy Act some supporting forms may have been removed from this thesis.

While these forms may be included in the document page count, their removal does not represent any loss of content from the thesis.
Conformément à la loi canadienne sur la protection de la vie privée, quelques formulaires secondaires ont été enlevés de cette thèse.

Bien que ces formulaires aient inclus dans la pagination, il n'y aura aucun contenu manquant.

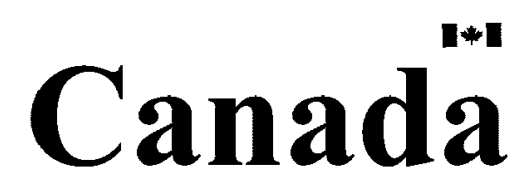




\begin{abstract}
The present study focused on examining the predictive ability of selected indicators of treatment readiness in antisocial youth, based on the models of antisocial behaviours developed by Loeber (1990) and Moffit et al. (1996). Several constructs of treatment readiness were examined, including the number of mental health problems, the onset of antisocial behaviours, the severity and persistence of antisocial behaviours, and aggression. Participants consisted of a sample of 115 behaviourally-challenged youth admitted to the Crisis unit at the Roberts/Smart Centre, an accredited residential mental health centre in the province of Ontario. The Treatment Readiness: Short Version (TR:SV) scale was used to obtain readiness scores. Results showed that an early onset of antisocial behaviours, the presence of a mental health disorder, gender, and past criminal behaviour were correlated with treatment readiness, but only early onset significantly contributed to the prediction of treatment readiness scores. Implications and limitations are discussed.
\end{abstract}




\section{Acknowledgements}

My sincere thanks and appreciation go to my advisor, Dr. Ralph Serin, for his support, input, and time dedicated throughout this project. Thanks are also extended to the members of the defence committee, Dr. Robert Hoge, Dr. Shelley Brown, Dr. Kevin Nunes, and Dr. Aaron Doyle, for their feedback and enthusiasm for this project. Special thanks are also due to Erik Gaudreault for his tremendous support and encouragement. 
Table of Contents

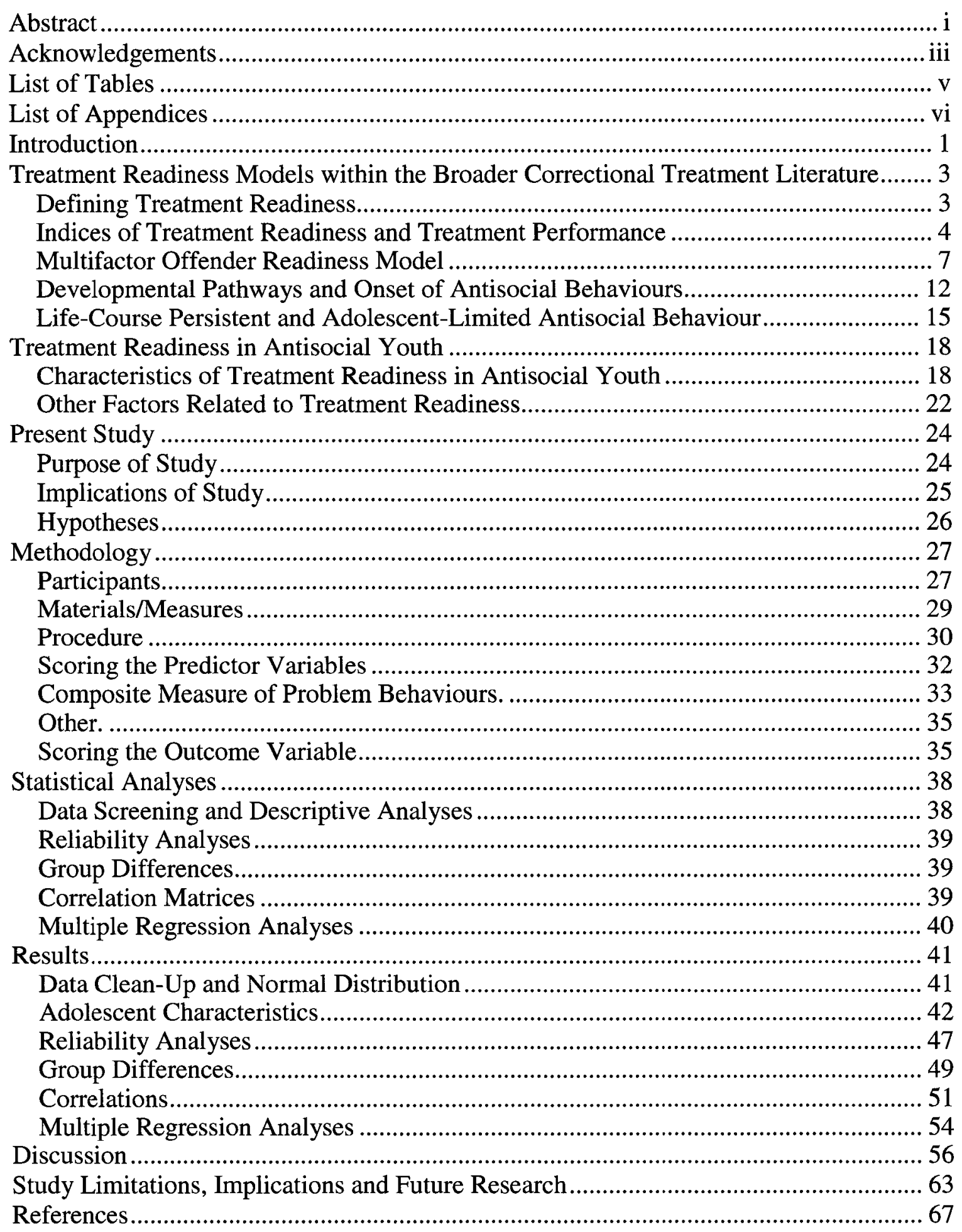




\section{List of Tables}

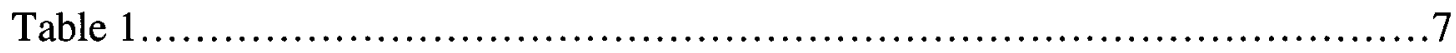

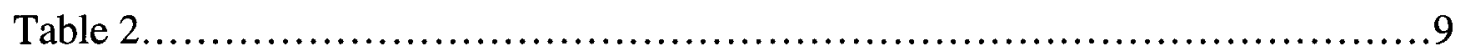

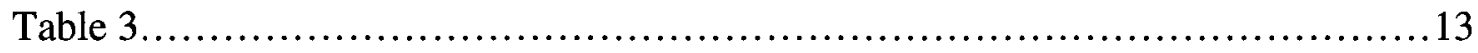

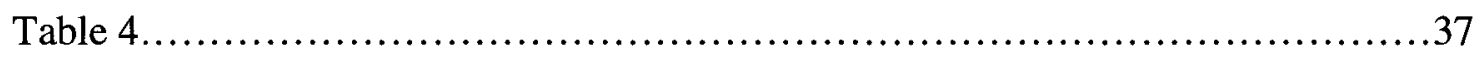

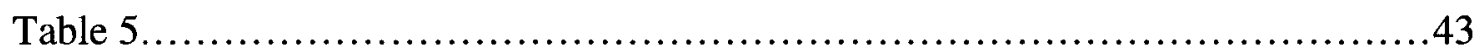

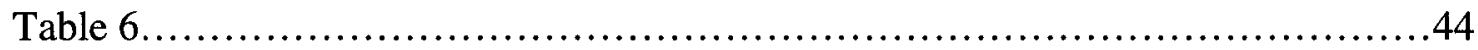

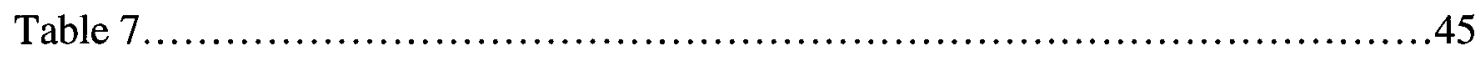

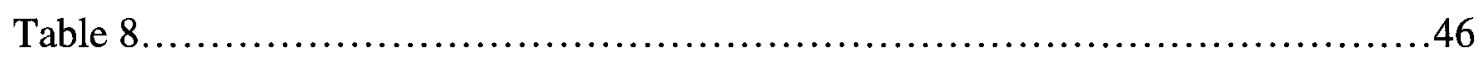

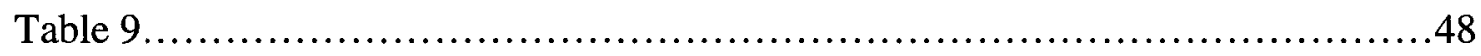

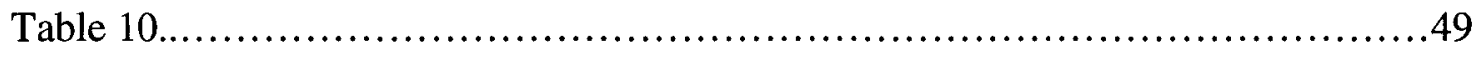

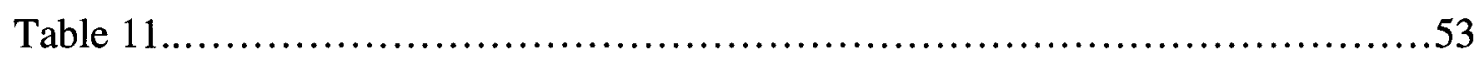

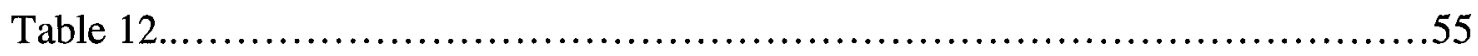




\section{List of Appendices}

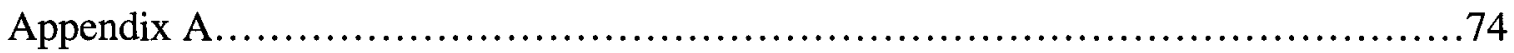

Appendix B................................................................. 87

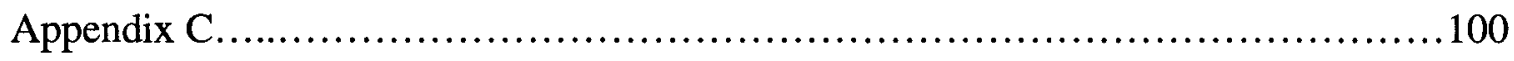

Appendix D.............................................................. 105 
Treatment Readiness in a Sample of Antisocial Youth: Assessing Characteristics for Use in Decision-Making

\section{Introduction}

The study of the externalization of antisocial behaviours in youth is well documented. Some degree of delinquent behaviour in childhood is considered as part of normal development when it is age-appropriate and allows children to learn from the consequences of their actions (Loeber, 1991; Moffitt, 1993). However, for a small proportion of youth, early adjustment and behavioural problems can persist into more serious manifestations of delinquent and criminal behaviour (Izzo \& Ross, 1990; Leistico \& Salekin, 1994; Loeber \& Hay, 1994; Steiner \& Dunne, 1997). There is empirical evidence for the stability of antisocial behaviours over time, and for difficulties in the ability to appropriately manage persistent antisocial youth (Carlson, Barr, \& Young, 1994; Gorske, Srebalus, \& Walls, 2003; Izzo, \& Ross, 1990; Leistico \& Salekin, 2003; Loeber \& Hay, 1994).

Because of the varying nature, causes and manifestations of antisocial behaviours, not all youth respond equally to treatment. The extent to which antisocial youth can benefit from treatment and desist from future delinquency is dependent on a number of factors, including those internal to the youth (developmental, behavioural, cognitive and social factors that affect how the youth will respond and remain in treatment) and external to the youth (e.g., development and methods of delivery of the program that have an impact of the effectiveness of the program) (Andrews, 2002; Antonowicz, \& Ross, 1994). Battjes, Onken, and Delany (1999) argue that a salient issue commonly 
overlooked by practitioners is a client's level of readiness to begin treatment, and that inattention to these needs can result in the inappropriate delivery of treatment, a lack of engagement in treatment, and treatment failure. Research within the broader correctional literature has shown that offenders who are unmotivated to begin treatment are less likely to succeed in treatment, and more likely to persist engaging in criminal behaviour (Sia, Dansereau, \& Czuchry, 2000; Serin, Kennedy, \& Mailloux, 2005; Williamson, Day, Howells, Bubner, \& Jauncey, 2003). Furthermore, they are less likely to desist because low treatment readiness hinders on long-term treatment effects (O'Leary \& Monti, 2004). Evidence shows that persistent antisocial youth are at a higher risk for treatment failure, and are less likely to desist in engaging in delinquent behaviours (Gorske et al., 2003; Izzo \& Ross, 1990; Loeber, 1991). Perhaps, because it is often the case that youth are referred to a mental health agency by someone other than themselves, they show hostility and resistance towards treatment. In order for antisocial youth to capitalize on potential treatment opportunities, it is important to ensure they are prepared to enter treatment. Conducting thorough readiness assessment and addressing these needs (i.e., giving advice on how to change) can increase their chance of completing treatment (Breda \& Heflinger, 2004; Marshall \& Moulden, 2005; O’Leary \& Monti, 2004; Sia et al., 2000).

There has been an increasing amount of interest in the identification of youth whose delinquent behaviours place them at risk for low treatment readiness. It is important to identify those who are less likely to succeed in treatment by assessing their level of readiness and motivation prior to determining the level and intensity of treatment needed (Carlson et al., 1994; Leistico \& Salekin, 2003). Nevertheless, research to date 
has yet to systematically explain the characteristics of antisocial youth as they relate to treatment readiness. As will be discussed, there is a great deal of progress to be made in this area, both on an empirical and a practical basis.

Treatment Readiness Models within the Broader Correctional Treatment Literature

\section{Defining Treatment Readiness}

Research in this area is fairly recent, and there remains some ambiguity in defining treatment readiness. Many researchers argue that the construct overlaps with that of others, such as treatment responsivity, treatment amenability, treatment preparedness, motivation, and treatability (Howells \& Day, 2003; Page \& Scalora, 2003; Serin, Kennedy, \& Mailloux, 2005; Ward, Day, Howells, \& Birgden, 2004). As such, the terms have been used interchangeably. In a recent definition, low readiness refers to "the presence of characteristics (states or dispositions) within either the client or the therapeutic situation, which are likely to impede engagement in therapy and which, thereby, are likely to diminish therapeutic change." (p. 320, Howells \& Day, 2003).

The responsivity principle of effective rehabilitation is especially relevant to treatment readiness (Andrews \& Bonta, 2003). Support for this principle has been derived from several meta-analyses that focus on specific offender populations including juvenile offenders (Dowden \& Andrews, 1999). An established finding in the literature is that treatment is more effective if the modes and styles of interventions are matched to client characteristics and criminogenic needs (specific responsivity). The offender who engages in treatment must be able to understand the contents of the program, and how to make use of newly acquired skills in their own environment (Andrews et al., 1990). Such 
factors to consider include motivation, learning styles, cognitions, personality style, etc. (Serin \& Kennedy, 1997).

Ward et al. (2004) argue that treatment readiness is a broader construct and involves motivation to enter treatment, understanding the need for treatment, and gaining specific skills needed to succeed in treatment. Likewise, Battjes et al. (1999) have also argued that there are specific behavioural processes associated with being prepared to enter treatment and being prepared to change one's behaviour. For instance, clients may initially display willingness to enter treatment, but once engaged, might be hesitant or less committed to changing their behaviours. These authors advise that both processes must be addressed separately in order to enhance the effects of treatment. To date, the construct of treatment readiness has been defined in greater detail by two important models, but only a few researchers have explored its application in correctional settings.

\section{Indices of Treatment Readiness and Treatment Performance}

As part of an effort to provide a systematic assessment of treatment readiness for high-risk offenders, Serin and Kennedy (1997) proposed a model containing several dynamic constructs contiguous to readiness and responsivity. In their model, treatment responsivity consists of treatability and treatment effectiveness. There are two pairs of constructs in treatability, namely, treatment motivation and readiness, and treatment compliance and participation. Similarly, there are two constructs within treatment effectiveness, namely treatment gains and treatment generalization.

Treatability refers to "the clinical determination of which patients (offenders), under what treatment modalities and environmental conditions will respond most favourably" (p. 8, Serin \& Kennedy, 1997). Also, readiness for treatment and motivation 
can be characterized as internal and external factors that affect one's desire to change, and can be measured by such factors as treatment interest, treatment goals, length of participation in a treatment program, dropout rates, etc. It is the "probability that a person will enter into, continue, and adhere to a specific strategy" (p. 10).

Serin and Kennedy (1997) note that some offenders appear willing to undergo treatment, but are more concerned with social desirability and avoiding the negative consequences associated with refusing treatment (i.e., longer incarceration). The model suggests that to effectively treat resistant clients, pre-treatment readiness activities targeting obstacles that impede engagement in treatment are needed (e.g., negative attitudes such as lack of empathy, minimization, rationalizations, denial of responsibility, enthusiasm for treatment, etc.). It is also important to make a distinction between treatment gains and treatment generalizations when assessing the effectiveness of interventions because even though one can learn new skills in treatment (gain), it then becomes a question of whether or not they are able to make use of these skills in their environment (generalization) in order to avoid relapse (Serin \& Kennedy, 1997).

Using multi-method assessment tools previously developed, Serin and colleagues set out to develop a protocol for treatment readiness, responsivity and participation (Serin, \& Kennedy, 1997; Serin, Kennedy, \& Mailloux, 2005). The Treatment Readiness, Responsivity, and Gain Scale: Short Version (TRRG:SV) was created and tested with a sample of 268 male and 29 female incarcerated offenders in a cognitivebased treatment program. The TRRG:SV was administered to measure readiness and responsivity gains before and after treatment. Results showed that women compared to men had higher mean readiness scores prior to treatment $(M=16.90$ and $M=12.54$, 
respectively) and after treatment $(M=21.86$ and $M=16.61$, respectively). Interestingly, the post-readiness levels of men were lower than the pre-readiness levels of women. It was also found that all of the women of the study had benefited to some extent from treatment gains, compared to only $28 \%$ of men, and that treatment gain scores were on average greater for women $(M=4.97$ compared to $M=3.59)$.

Responsivity factors and treatment gains were also measured using interviewbased assessments and questionnaires in another incarcerated sample (Serin \& Kennedy, 1997). In total, 72 offenders were included in the study, of which 21 were treated sex offenders, 20 untreated sex offenders, and 31 treated non-sex offenders. Results showed that most offenders, especially sex offenders, were low on readiness both prior to and after treatment. Furthermore, the assessment of treatment gains from an offender's perspective varied from that of the clinician's. This pilot study needed further replication as several potential limitations were identified, including small sample size, lack of treatment standardization, lack of interrater reliability, and absence of recidivism data. The authors concluded by suggesting that a set of guidelines be established for interviewbased assessments of treatment readiness and tested in a variety of offender samples to identify specific targets, as the eventual goal is to establish an empirical relationship between treatment readiness, responsivity, and risk-need assessments. Serin (1998) has proposed several treatment readiness and performance indices to serve as a basis for future research (see Table 1). 
Table 1

Indices of Treatment Readiness and Treatment Performance proposed by Serin (1998)

Constructs

Indices

Treatment Readiness

Treatment Performance problem recognition, goal setting, motivation, selfappraisal, expectations, behavioural consistency, views about treatment, self-efficacy, dissonance, external supports, affective component

knowledge of program content, skills acquisition, disclosure, confidence, knowledge application, skills application, understanding of criminality, motivation, insight, attendance, disruptiveness, appropriateness, depth of emotional understanding, participation

\section{Multifactor Offender Readiness Model}

Howells and Day (2003) argue that the notion of treatment readiness implies that certain internal and external conditions exist before engaging in treatment (i.e., psychological and behavioural states, treatment setting and therapeutic alliances), whereas the notion of responsivity refers to obstacles that prevent an offender from engaging or being responsive to treatment. Based on Prochaska and DiClemente's (1982) Stages of Change Model, the Multifactor Offender Readiness Model proposed by Ward et al. (2004) argues that readiness also implies having acquired the necessary cognitive, behavioural and emotional skills needed to benefit from treatment (for 
example, developing vocabulary skills to be able to better describe thoughts, emotions, and behaviours). Combined with contextual factors, these can either facilitate or hinder program engagement (attendance, participation, therapeutic alliance, and attrition) and program performance (change in criminogenic needs and recidivism).

Howells and Day (2003) have identified potential impediments to treatment readiness, including the complexity of cases in terms of presenting mental health problems, psychopathic traits and comorbidity of mental health disorders, setting factors, attitudes and beliefs regarding behaviours (lack of problem recognition and responsibility-taking), compulsory or mandatory engagement in treatment, and the perception that treatment is not necessary or helpful. Building upon this work, Ward et al. (2004) have incorporated these factors into a model for assessing readiness in offenders, which are shown in Table 2, and are assumed to have a direct impact on readiness for treatment (engagement and performance). Some dimensions are considered to be internal to the offender (e.g., cognitive, affective, behavioural, volitional, and identity factors), and some dimensions are considered to be external to the offender (e.g., circumstances, location opportunities, resources, support, and program characteristics). To ensure readiness for treatment, the authors recommend targeting attitudes, problem recognition skills, decision-making skills, and motivation. These recommendations are similar to those provided by Battjes et al. (1999), who argue that targeting attitudes towards treatment, motivation to seek treatment, and perceptions of the necessity of treatment are necessary to ensure readiness. These recommendations are also implicit in Serin and Kennedy's (1997) work and explicit in specialized violent offender programming (Preston \& Murphy, 1997). 
Table 2

Internal and External Factors Related to Readiness for Treatment as Proposed by the Multifactor Offender Readiness Model (Ward et al., 2004)

Factors

Internal

Cognitive: attitudes, beliefs, cognitions, resistance to change, expectations.

Affective: emotional dysregulation, hostility, distress, empathy.

Behavioural: willingness to change, recognition of problem and seeking help.

Volitional: personal goals compatible with rehabilitation goals, motivation to change.

Personal Identity: self-esteem, autonomy, basic values.

\section{External}

Circumstantial: compulsory/mandated treatment, perceived level of coercion.

Location: prison, residential or community setting.

Opportunity: availability of programs.

Resources: quality of program, quality of specialized training for therapists.

Support: social/interpersonal support available to offender that encourages change.

An important strength of the model is its focus on cognition and the distinction it makes between readiness to enter treatment and readiness to change. As previously stated, Battjes et al. (1999) argue that it is critical to differentiate between these two constructs. The assertions of the Multifactor Offender Readiness Model are consistent with research findings that have examined the relationship between cognitions and motivation. Blankenship, Dansereau, and Simpson (1999) studied 493 adult probationers 
in a residential drug abuse program who were assigned to either a cognitive-based readiness or standard treatment program. They found that the cognitive-based readiness program was more successful in increasing probationers' motivation for treatment compared to the standard drug abuse program.

Williamson et al. (2003) have measured the psychometric properties of the Multifactor Offender Readiness Model on a sample of 418 adult males participating in 32 different anger management programs. The Anger Readiness to Change Questionnaire (ARCQ) was administered prior to and after the delivery of treatment, an instrument based on Prochaska and DiClemente's (1982) Stages of Change Model. Attrition was a factor, and at follow-up, 285 offenders participated in the study (220 in the anger management sample, and 65 control subjects). Validity analyses showed that the ARCQ has strong convergent validity with the TRRG:SV, but moderate construct validity. It was found that those who were high on pre-contemplation and low on contemplation and action were lower on readiness, compared to those who were high on contemplation and action and low on pre-contemplation. Their results also showed that offenders who scored high in readiness prior to the delivery of treatment were more likely to gain from the benefits of treatment than those who scored low on readiness. However, no differences in gains were found between the anger-based management group and the control group. These authors also found that an increase in readiness did not readily translate into a reduction in anger problems, indicating that the effectiveness of the program is not necessarily dependent on changes in readiness, and that treatment gains could potentially be enhanced with a more effective program. 
It is important to note that both models put forward by Serin and Kennedy (1997) and Ward et al. (2004) are based on adult offender populations. Studies with juvenile samples are limited, but findings do not necessarily emphasize the need for an agespecific measure of treatment readiness. Consistent with Serin and Kennedy's (1997) model, Carlson et al. (1994) found that treatment compliance was significantly associated with problem recognition skills, positive treatment behaviours (showed greater rule compliance, cooperation, and fewer problem behaviours), and greater social support in antisocial youth. However, some caution is warranted, in that factors of low treatment readiness in antisocial youth may differ from those of adult offenders. For example, O'Leary and Monti (2004) found in a review of motivational techniques that youth problem drinkers experience fewer negative consequences as a result of their behaviour as compared to adult problem drinkers, and as a result, were less likely to respond to feedback on their abuse of alcohol and its effect on their health. They also had greater difficulties in establishing future goals and identifying potential barriers to the achievement of these goals. These authors argue that the underlying causes of the emergence of drinking behaviours in youth differs from that of adult problem drinkers, given that the proportion of youth with drinking problems who are also delinquent is greater that the proportion of adult problem drinkers who are also offenders (O'Leary \& Monti, 2004).

Russell (2005) found that age acted as a mediating factor between motivation and long-term treatment retention. Youth substance abusers were less internally motivated and required more time to complete treatment compared to adult substance abusers. These findings are also consistent with that of other studies (see DeLeon, Melnick, 
Kressell \& Jainchill, 1994), indicating that although motivation may be an important measure of readiness, antisocial youth are even less likely to be motivated than adults. Understanding a youth's ability to be ready for treatment also implies understanding the underlying developmental and behavioural factors that affect their ability to be ready. As previously mentioned, much still remains to be known about treatment readiness in antisocial youth. If readiness and motivation have been linked to treatment gains, then the key characteristics that contribute to low readiness must also be identified. A closer examination of developmental models of antisocial behaviours will provide leads for exploratory research.

Developmental Models of Antisocial Behaviours

\section{Developmental Pathways and Onset of Antisocial Behaviours}

There is strong evidence that an earlier onset of conduct problems is associated with serious and chronic antisocial behaviours in adolescence and low treatment readiness (Carlson et al., 1994; Loeber \& Hay, 1994; Loeber, Stouthamer-Loeber, \& Green, 1991; Moffitt, 2003; Moffitt, Caspi, Dickson, Silva, \& Stanton, 1996; Moffitt, Caspi, Harrington, \& Milne, 2002; Shamsie, Sykes, \& Hamilton, 1994; Taylor, Iacono, \& McGue, 2000). The earliest model of onset of antisocial behaviours emerged in the mideighties with Patterson's (1986) Coercion Theory and Performance Model of aggressive antisocial behaviours in children, which states that early starters (below age 6) exhibit defiant and coercive behaviours, school failure and involvement with deviant peer groups. Building upon this work, Loeber and colleagues proposed a model for categorizing disruptive behaviours in youth into specific developmental pathways (Loeber, 1990; Loeber \& Hay, 1994, Loeber, Keenan, \& Zhang, 1997) (see Table 3). 
Table 3

Competing Onset Models of Antisocial Behaviours and Their Focus

Models

Loeber (1990)'s Developmental Pathways Model of Antisocial Behaviours - Markers for Continuity of Antisocial Behaviour (onset before age six, frequency, and severity)

- Non-Aggressive: escalation from minor covert behaviours (e.g., lying and shoplifting), to moderately severe covert behaviours (e.g., property damage), to serious delinquency (e.g., fraud and burglary). Also consists of conflict with authority (e.g., stubbornness, defiance and authority avoidance).

- Aggressive/Versatile: escalation from minor aggressive behaviours such as (e.g., bullying and intimidating others), to more serious forms of physical aggressiveness and fighting, and serious violent behaviour (e.g., assault, rape).

Moffitt's (1993, 2003) Life-Course Persistent (LCP) and Adolescence-Limited (AL) Model of Antisocial Behaviours

- Life-course persistent: childhood onset and persistence through adolescence and adulthood; characterized by neurocognitive and psychosocial impairments.

- Adolescence-limited: adolescent-onset of antisocial behaviours caused by environmental stressors that result in rebellious acts and a desire for autonomy.

- Childhood-limited: persistent antisocial behaviours are limited to childhood but also engage in some delinquency in adolescence; tend to be anxious, avoidant, dependant, low in intelligence, and socially isolated.

Developmental pathways are defined by Loeber et al. (1997) as "stages of behaviour that unfold over time in a predictable order" (p. 322). The Pathways Model assumes that there are sequences of disruptive behaviours during childhood that gradually increase in frequency and severity over time. It argues that children who begin to display 
antisocial behaviours at an early age are more likely to follow an aggressive/versatile pathway to delinquency, whereas those who begin displaying antisocial behaviours during adolescence tend to follow a non-aggressive pathway.

Finally, the model argues that youth with longer histories of antisocial behaviours are less likely to respond to treatment, and therefore, will be more challenging to treat (Loeber, 1991). The early identification of these youth would assist clinicians in identifying youth who would benefit from a readiness assessment to ensure their needs (e.g., problem recognition, motivation) are addressed prior to and during treatment.

Several studies have provided support for the model proposed by Loeber and Hay (1994). Loeber et al. (1991) examined the relationship between early onset and characteristics of later conduct problems in a sample of 205 boys over a five-year period. Results showed that boys who had an early onset of problem behaviours had twice the official reported rates of delinquency at follow-up and were also much more likely to engage in some form of serious delinquency compared to those who had a later onset of antisocial behaviours. Approximately $25 \%$ of those who had an early onset also had more than one conviction at follow-up. Aggressive/hyperactive youth were also more likely than those with either one of these two factors to engage in serious delinquency. In a more recent study, Loeber and colleagues identified age trends in the onset and prevalence of aggression (Loeber et al. 1997). Three onset curves were identified, namely, minor aggression (bullying and annoying others), fighting (physical and gang fighting), and violence (attacking someone, forced sex). With a sample of 503 boys, they found that as the age of onset for aggressive behaviours increases, so does the level of severity of these behaviours. Furthermore, they found that the ordering of the severity of 
aggressive behaviours also varied with age. For instance, minor aggression was common between the ages of three and 16 , whereas the onset of physical fighting usually began around the age of 10 , followed by the onset of violence at age 11. Severe aggression such as violence was not as likely to emerge in earlier stages of life. Similarly, Tolan and Gorman-Smith (1998) found in their study that age of onset and presence of childhood behaviour problems differentiated violent and serious offenders from non-aggressive offenders.

An important strength of this model is its emphasis on risk factors. Regardless of the path that is followed, the higher the exposure to a risk factor, the higher the risk for engaging in serious delinquency; also, the higher the risk the youth will be unmotivated for treatment. The model however fails to identify youth whose problematic behaviours are temporary or opportunistic (e.g., aggression caused by provocation). They are most often referred to in the literature as 'experimenters' or 'transitory' delinquents, and may differ from chronic youth in their treatment readiness needs. Loeber and Hay (1997) however acknowledge the existence of this pathway and propose that the term 'escalation' be distinguished between two types, namely long-term escalation (disruptive behaviours characterized by a gradual development from minor to more serious forms of aggression), and short-term escalation (serious violence without any previous antecedents). The authors' suggestions are supported and explained by a model developed by Moffitt and colleagues (Moffitt, 1993, 2003; Moffitt et al., 1996).

\section{Life-Course Persistent and Adolescent-Limited Antisocial Behaviour}

Research examining children's histories provides support for the argument that those who show disruptive problems early in childhood are more likely to persist into 
adolescence and adulthood. Shown in Table 3 is the model of life-course-persistent (LCP) and adolescence-limited (AL) offending developed by Moffitt and colleagues for identifying youth who are at risk for serious delinquency (Moffit, 1993, 2003; Moffitt et al., 1996). This model primarily adopts an etiological perspective to delinquency and suggests that there is a group of youth whose antisocial behaviours begin early in childhood and persist through adolescence and adulthood, and one group whose antisocial behaviours begins and ends in adolescence. Moffitt et al. argue that children with early and late onset of conduct problems differ significantly in personality and temperament measures as early as age three.

According to Moffitt (2003), an early onset of conduct problems is associated with neurocognitive and psychosocial impairments (e.g., cognitive deficits, motor difficulties, aggressive personality, difficult temperament, hyperactivity, lower verbal IQs, previous abuse and neglect), as well as environmental risk factors (e.g., low socioeconomic status/social disadvantage, family conflict, low parental discipline, harsh or neglectful parenting, rejection from peers), whereas a later onset is mainly associated with environmental factors. Later onsets can be further characterized by emerging environmental stressors that result in rebellious behaviours driven by a desire for autonomy. A significant amount of environmental risks, such as low parental monitoring, combined with less neurological impairment, are stronger predictors of adolescent onsets of antisocial behaviours (Raine et al., 2005).

In a longitudinal study, Moffitt et al. (1996) studied 457 boys from the ages of three to 18 years. They demonstrated that an early onset of antisocial behaviours was associated with a difficult temperament at a younger age, higher levels of violence in 
adolescence, higher levels of psychopathic traits and less potential for amenability to treatment. Furthermore, deficiencies such as lack of self-control, an abnormal development of language, memory problems were common with this onset. Therefore, the ability to respond to difficult social situations is impaired, and youth often resort to aggression and violence to solve problems.

There also appears to be gender differences between LCP and AL groups. For example, Fergusson et al. (2000) found delays in the development of antisocial behaviour in girls, and that fewer girls belong to LCP groups. Girls who belonged to the LCP group resembled their male counterparts in neuropsychological and family backgrounds, suggesting that some risk factors may overlap within gender. One possible explanation is that the risk factors associated with antisocial behaviours are present in childhood for both boys and girls; however in girls, these effects may be much more covert until later in adolescence, as compared to boys who typically show more overt behaviours at an earlier age.

Moffitt et al. (1996) argue that AL youth are less difficult to treat and are more likely to desist from crime as they enter young adulthood, compared to youth who have had serious conduct problems since childhood. They found that only $6 \%$ of the LCP youth in their study had desisted by the age of 18 . The results of Donnellan, Ge, and Wenk's (2000) study found that AL youth had greater cognitive abilities that contributed to earlier positive adjustment, which acted as a protective factor for treatment readiness. Moffitt et al. (1996) also argue that AL youth are less difficult to treat because their antisocial behaviours are not as deeper-rooted as those of the LCP youth. As such, they may require fewer pre-treatment readiness activities than LCP youth. 
However, there is also some evidence for the desistance of antisocial behaviours of LCP youth over time (Sampson \& Laub, 2003; Stouthamer-Loeber, Wei, Loeber, \& Masten, 2004). For example, the results of the Stouthamer-Loeber et al. study showed that about one-third of their sample became serious persistent delinquents between the ages of 13 and 19 , however, $40 \%$ had desisted by the ages of 20 to 25 . This suggests that the treatment of early and late onset youth can be effective, but is dependent on the nature of the youth's symptoms and deficits (Moffitt, 2003). Readiness assessments, informed by an onset model, could help ensure that the treatment needs of LCP youth are adequately addressed, and consequently ensure longer lasting treatment effects comparable to that of AL youth.

Treatment Readiness in Antisocial Youth

\section{Characteristics of Treatment Readiness in Antisocial Youth}

Many researchers argue that motivation to change is low amongst antisocial youth. Russell (2005) examined the readiness and motivation levels of youth and adults with substance abuse problems who entered treatment, as well as their willingness to change their behaviours and complete treatment. It is important to note that this author makes a distinction between readiness and motivation, rather than the latter being a subcomponent of the former. The goal of the study was to determine if there was a relationship between motivation and readiness across different age groups, and if these factors were significant predictors of treatment retention. Three groups were included in the study: a sample of 441 youth age 19 and under, a sample of 1458 young adults age 19 and over, and a sample of 656 youth from a separate substance abuse program. The authors found that dynamic characteristics (e.g., readiness needs) were better predictors 
of treatment retention compared to static or other fixed factors such as age. However, in some cases, age acted as a mediating factor between motivation and long-term treatment retention.

Similar to the conclusions of DeLeon et al. (1994) and Russell (2005), Breda and Heflinger (2004) also argue that a large proportion of antisocial youth are unmotivated to change. This is perhaps because they do not perceive the benefits or the necessity of treatment (Carlson et al., 1994; Gorske, Srebalus, \& Walls, 2003; Russell, 2005). Thus, attending to readiness and motivation can be challenging. The literature suggests that there are also differences in the readiness needs of older and younger youth. It is argued that older youth have better acquired important cognitive abilities needed to benefit from treatment (e.g., problem-solving skills, understanding material being taught, and understanding feedback) (Leistico \& Salekin, 2003). Page and Scalora (2003) found in their study that abstract reasoning was associated with a greater understanding that consequences are a result of one's own actions, which in turn was associated with greater readiness for treatment. O'Leary and Monti (2004) also argue that those who are younger may not have reached important cognitive-developmental milestones needed to benefit from treatment, and therefore are more likely to score low in treatment readiness. However, as the juvenile literature suggests, it may not be the actual age of youth that will predict readiness for treatment, but rather the age of onset of antisocial behaviours. As Moffit et al. (1996) note, youth with an adolescent onset of antisocial behaviours are more cognitively skilled, and are predisposed to higher readiness levels. This can be partially explained by studies conducted on motivation for treatment and mental health diagnoses in youth. The number of mental health disorders has been found 
to be related to low motivation for treatment in older youth (Kann \& Hanna, 2000; Kazdin, 1993). Comorbid youth were also more likely to have an earlier onset of antisocial behaviours and cognitive deficiencies (Kazdin, 1993). Therefore, they may also require pre-treatment readiness training because these factors may place them at a similar readiness level as younger children. Hence, early onset and cognitive deficiencies, rather than age, may be a better predictor of low treatment readiness.

Breda and Heflinger (2004) have also examined the relationship between age, motivation and change in substance-abusing behaviours. A large proportion of youth in their study had low to moderate levels of motivation, showed to be high on extrinsic motivation and low on intrinsic motivation, and had negative perceptions of the necessity for treatment. Age was not directly related to motivation; they found that the best predictor of motivation was the number of negative consequences experienced as a result of their substance-abusing behaviours. When conducting assessments, consequential thinking is therefore an important readiness factor. These findings are consistent with other studies in the literature that emphasize the role of cognitions in predicting treatment readiness (Carlson et al., 1994; Leistico \& Salekin, 2003; O’Leary \& Monti, 2004). Several other researchers have examined the role of cognitions, and conclude that those who rationalize or externalize the blame for their actions are not as likely to be ready to begin treatment as those who have acknowledged and taken responsibility for their behaviours, or those who have a desire to engage in treatment and change their behaviours (Carlson et al., 1994; Page \& Scalora, 2003).

In a study conducted by Carlson et al. (1994), the relationship between antisocial attitudes of young offenders and treatment amenability was examined. The goal was to 
gain an understanding of whether or not cognitive and behavioural characteristics of antisocial youth are predictive of better treatment outcomes. These researchers argue that the most antisocial and delinquent youth, especially those with longer criminal histories, are the most difficult to treat. The study hypothesized that youth who admitted to having a problem at intake and/or those who had taken responsibility for their actions would score higher in treatment amenability than those who denied their problems.

A total of 84 young offenders and their parents participated in the study. Those who completed at least four months of cognitive treatment were included in their study. Staff members collected data on the youth's level of involvement in the program as well as outcome data at discharge. Data regarding the youth's background was also collected at intake (e.g., race, criminal history, substance use, mental health problems). Treatment amenability was measured using the Youth Amenability to Treatment (YAT) scale, a measure similar to the one developed by Serin and colleagues (Serin, \& Kennedy, 1997; Serin, Kennedy, \& Mailloux, 2005). Results showed that approximately one-third of youth in their study failed to complete treatment. Three-quarters denied difficulties and responsibility for their problems, but $80 \%$ were optimistic about obtaining treatment. Carlson et al. (1994) point to the contrast between the high proportion of denial of problems and the high proportion of youth who report at least some possibility of being helped. They found that treatment amenability was associated with older youth who showed greater rule compliance, fewer problem behaviours, and whose parents showed more positives attitudes towards the youth's ability to change.

While their study did not find a direct relationship between treatment amenability, treatment completion and recidivism, criminogenic risks/needs functioned as mediating 
factors. These authors argue that it is not just the impact of static factors such as age at first offence or IQ but also cognitive, attitudinal or dynamic factors that have an impact on amenability treatment. However, they also argue that "a counselor might work less diligently to form a therapeutic relationship with non-amenable clients. To conclude early on that some youth or families are amenable while others are not could lead to different interventive behaviours that would not serve clients well." Adopting such a clinical stance that assumes that all youth respond equally to treatment is an infringement on the notion that responsivity factors are critical to treatment efficacy.

\section{Other Factors Related to Treatment Readiness}

Gorske et al. (2003) investigated the relationship between adolescent characteristics, level of behavioural severity and treatment effectiveness. The sample consisted of 150 antisocial youth in community mental health agency. Level of behavioural severity was measured using the Child and Adolescent Functional Assessment Scale (CAFAS), an instrument used to determine the appropriate level of treatment. The level of success at discharge (clinical judgement of the youth's perception that their treatment goals have been achieved) determined treatment readiness. It should be noted that this outcome measure had the potential for judgment bias; hence findings regarding treatment outcomes must be interpreted with caution.

The sample was on average 16 years of age, consisted predominantly of girls, and a good proportion had been diagnosed with a mental health disorder. The vast majority of these youth displayed a great deal of behavioural problems and were not able to function in a regular home or school environment. Approximately two-thirds of youth received a combination of individual, group, and family therapy. The findings showed 
that a significant number of youth had been successfully discharged (64\%), and that family support in treatment was a key component of success. However, those who had serious behavioural problems (i.e., engaged in law violations, assaultive or delinquent behaviours) were less likely to have been successfully discharged. The authors argue that these youth are at a higher risk for treatment failure because they suffer from particular emotional and behavioural difficulties as a result of their environment that place barriers on the achievement of their treatment goals.

Consistent with this research, Leistico and Salekin (2003) have shown evidence for specific historical, behavioural, and personality predictors of treatment readiness. Their study was the first to measure the validity of a tool for assessing treatment amenability in youth, namely, the Risk, Sophistication-Maturity and Treatment Amenability Instrument (RST-i). The RST-i consists of three subscales (risk, sophistication-maturity, amenability to treatment) with a combined total of 45 items assessing antisocial behaviours, attitudes toward antisocial behaviours, personality factors, and environmental influences. Amenability to treatment was defined as having higher levels of motivation to engage in treatment, a genuine interest in change, recognition of problems and expressions of guilt, treatment expectations, and family support/stability. It is important to note however that this instrument has been primarily used in the context of juvenile transfers to adult courts rather than for treatment planning.

The clinical files of approximately 125 boys residing in a juvenile treatment facility were examined and information was collected from intake assessments, psychological evaluations, criminal history reports, school reports, etc. According to their results, the RST-i had moderate construct and criterion validity, but scores were 
significantly predictive of transfers to adult courts. Several important findings emerged from this study. Their results showed that amenability to treatment was significantly correlated with age of onset, frequency and severity of antisocial behaviours, criminal behaviours, IQ, academic achievement, negative attitudes, and diagnosis of CD. That is, youth who were low in treatment amenability were more likely to have an early onset of conduct problems, a higher number of (and more sophisticated) antisocial acts, a criminal history, low IQ, display negative attitudes, a diagnosis of $\mathrm{CD}$, as compared to youth who scored higher in treatment amenability. Interestingly, involvement in both violent and non-violent behaviours reduced treatment amenability.

It is important to note that few studies have examined whether or not gender differences exist in readiness, motivation or amenability to treatment. Because there are a limited number of studies that have examined the developmental and behavioural characteristics of youth as they relate to treatment readiness, researchers point to the importance of investigating this matter in greater detail.

\section{Present Study}

\section{Purpose of Study}

The focus of the present study was to examine the predictive ability of selected indicators of treatment readiness in antisocial youth. The goal was also to determine to what extent specific developmental and behavioural characteristics best predicted low treatment readiness. The literature has identified several potential factors, including examining the complexity of presenting mental health problems (O'Leary \& Monti, 2004), the onset of antisocial behaviours (Carlson, Barr \& Young, 1994; Leistico \& 
Salekin, 2003; Loeber, 1990; Moffitt et al., 1996), the severity and persistence of antisocial behaviours (Gorske et al., 2003; Leistico \& Salekin, 2003; Moffitt et al., 1996; O’Leary \& Monti, 2004), and aggression (Leistico \& Salekin, 2003).

\section{Implications of Study}

The main contribution of this study was to identify specific developmental and behavioural characteristics of antisocial youth that should be taken into consideration when assessing readiness for treatment. The studies conducted by Gorske et al. (2003) and Leistico and Salekin (2003) were the first to explore in a wide range of predictors of treatment readiness for delinquent youth, and further research is required to determine if these findings can be applied across different juvenile samples. The present study also examined the relationship between a number of developmental and behavioural characteristics of delinquent youth and treatment readiness, which will contribute to future experimental research in this area. This study used however a conceptuallyderived measure of treatment readiness that has only been validated with adult offenders. Therefore, it will also contribute to determining if the construct of treatment readiness, as defined by the Serin and Kennedy (1997) model, also predicts readiness in a delinquent juvenile sample.

Understanding the direct and indirect relationships of the best predictors of treatment readiness will assist in the development and refinement of age-appropriate theoretical frameworks and models of treatment readiness for antisocial youth, and help in the establishment of assessments of treatment readiness. As previously stated, assessing readiness needs is also a critical step in determining the appropriate level of treatment (e.g., type, length, and intensity of treatment). This type of research will 
generate knowledge that will help contribute to enhanced program performance, by allowing the identification of youth who are potentially low on readiness to be selected for assessment and readiness-based intervention when required. This in turn should help reduce the number of program failures due to low readiness. Hence, the goal is to help guide clinical practice to a more empirically-demonstrated application of treatment readiness models, and to improve program efficacy and efficiency.

\section{Hypotheses}

Based on the review of the literature and the developmental models of antisocial behaviours, the present study hypothesized the following:

1) The mean treatment readiness scores of youth with an early onset of problem behaviours will be significantly lower than the mean treatment readiness scores of youth with an adolescent onset of problem behaviours.

2) The number of mental health disorders will be negatively related to treatment readiness scores.

3) Higher scores on the index of severity will be related to lower treatment readiness scores.

4) The number of risk markers will be negatively related to treatment readiness scores.

5) The mean treatment readiness scores of aggressive youth will be significantly lower than the mean treatment readiness scores of non-aggressive youth. 6) A higher number of risk markers (early onset, frequency of antisocial behaviours, severity of antisocial behaviours, and multiple settings), the presence 
of a mental health disorder, and higher scores on the composite measure of problem behaviours will be the best predictors of low treatment readiness.

\section{Methodology}

\section{Participants}

Participants in the present study consisted of a sample of 115 behaviourallychallenged youth who were admitted to the Roberts/Smart Centre (RSC), an accredited residential mental health centre in the province of Ontario. The RSC accepts referrals of adolescents (from any parent or professional, or from the adolescent him or herself), between the ages of 12 and 17 living in Ontario who are experiencing significant problems in one or more of the major areas of life functioning (personal/family, school, or community), including those who have received open custody dispositions from the courts (young offenders). Adolescents under the age of 16 are required to obtain parental/legal guardian consent in order to receive treatment services. The Centre offers clinical assessments and therapeutic services, operates a Crisis Centre ${ }^{1}$, as well as several treatment residences, a Learning Academy, and a substance-abuse program.

The sample of youth for this study was drawn amongst those previously admitted to the Crisis centre, a 5-day closed-custody residential placement for youth who are temporarily incapacitated (e.g., would cause harm to themselves or others). These include youth who are overly defiant, uncontrollable, aggressive and/or suicidal. Family members (e.g., biological parents, other family members, foster parents) are the predominant source of referrals. The Crisis youth were the target population for this

\footnotetext{
${ }^{1}$ The Crisis Centre at RSC closed on March $31^{\text {st }}, 2006$, and resumed operations at the Youth Services Bureau (YSB) of Ottawa, ON.
} 
study because they were not in a program that provided exposure to some type of treatment, and therefore, readiness levels could be measured without the effects of treatment influencing the scores.

Upon admission to the RSC, pertinent documentation and information is collected as a part of the agency's standard procedures. Psychological and behavioural interviews (individual and/or family) are conducted to assist in planning the course of action or treatment (depending on the program) during their stay at RSC. The purpose of the individual interview is to gain a better understanding as to what problems are at hand by discussing with the youth what they perceive are their areas of difficulties, whereas the family interview is conducted to obtain information regarding family background and parental attitudes towards their child's behaviour. Youth admitted to the Crisis centre also complete a self-reported questionnaire.

Participants for this study were selected among those who met the following criteria:

(1) Were admitted to Crisis between March $31^{\text {st }}, 2005$ and March $31^{\text {st }}, 2006$.

(2) The referral to Crisis was made by a family member (biological parents, other family member, or foster parents).

(3) The Structured Client Information System (SCIS) and the youth self-report Crisis Interview Form (CIF) was completed at intake.

(4) The Crisis Daily Log was completed (by the clinician) for each day the youth resided in Crisis. 


\section{Materials/Measures}

The SCIS is a client tracking and monitoring system for problem youth. It was designed to support the planning and delivery of youth services, to maintain clientoriented case records and central files, and to produce client-tracking reports to assist the Ministry of Children and Youth Services in the collection and reporting of data. It holds a complete inventory of the youth's developmental, familial, behavioural, and mental health background, and is completed by the intake coordinator during the intake interviews. The SCIS was used to collect information for this study because it is completed for each youth during admission to the RSC, and therefore, is a consistent source of information. This scale was specifically developed to capture information regarding key variables found in the developmental literature (e.g., age of onset, frequency and severity of antisocial behaviours, mental health diagnoses, etc.). Sections of interest include: Client Demographics, Presenting Problems, and Presenting Strengths (Annex A).

Treatment readiness was measured using the Treatment Readiness: Short Version (TR:SV) subscale of the Treatment Readiness, Responsivity and Gain Scale: Short Version (TRRG:SV) (Annex B). Serin, Kennedy, and Mailloux (2005) developed the instrument as a response to a need for a systematic assessment of treatment readiness in offenders, as well as to provide assistance in treatment planning. The TR:SV was used for the present study because it measures both readiness to enter treatment and readiness to change, and because it has been both operationalized and tested with several samples of offenders. 
Approximately 50 items for the scale were initially obtained through factor analyses with a sample of male offenders in a cognitive skills program. The number of items was subsequently reduced while keeping the overall internal consistency of the scale intact $(\alpha=.82)$. Strong correlations between the short and long versions of the instrument were also found $(r=.97)$ (Latendresse, 2006). The most recent version of the TR:SV consists of eight items, namely, problem recognition, benefits of treatment, treatment interest, treatment distress, treatment goals, treatment behaviours, motivational consistency, and treatment support. The authors of the instrument report excellent internal consistency for this domain $(a=.83)$, which also produced favourable factor loadings with correlations amongst items ranging from .60 to .77 .

Information used to score the TR:SV was obtained using the CIF, a 9-item youth self-report questionnaire completed upon admission to Crisis (Annex C), and the Crisis Daily Log, a day-to-day account of the activities and behaviours of youth throughout their stay at Crisis (i.e., follows rules and regulations, participates in group activities). The questionnaire seeks to determine youth's treatment readiness needs; however, assessments are based on clinical judgments rather than assigned scores. Hence, the information found in the CIF was used to score the TR:SV. To date, the instrument developed by Serin, Kennedy and Mailloux (2005) has only been used with adult offenders, and therefore, the present study will be the first to use the TR:SV with a sample of antisocial youth.

\section{Procedure}

This study made use of a retrospective correlational design. Since the implementation of the Youth Criminal Justice Act, admissions into custody placements 
without a treatment component have decreased substantially. Combined with the closing of the Crisis Centre in March 2006, a prospective design was not feasible. However, there are several advantages to using a retrospective correlational design to predicting pre-treatment readiness scores, including the potential for greater flexibility in examining complex relationships between variables that cannot be manipulated. Two important disadvantages should also be considered, namely, the lack of randomization of participants to groups, and the inability to make inferences about cause and effect (e.g. reasons for the associations between variables are unclear).

Upon admission, all youth records are entered into an electronic database of RSC clients. Phase one of sample selection involved deriving from this database a list of youth admitted to Crisis between March $31^{\text {st }}, 2005$ and March $31^{\text {st }}, 2006$. Admission to the Centre requires that youth and parents give consent in tandem to the secondary use of their biographical data for research purposes. Therefore, no additional parental or youth consent was required for data collection. Sample size was determined using the general rule-of-thumb for studies using regression analyses, namely $N>50+8(\mathrm{~m})$, where $N=$ sample size and $m=$ number of predictor variables ${ }^{2}$. Because there are six predictor variables, this indicates that a sample size of at least 100 youth was needed. When case files did not meet the study criteria, they were excluded from the sample. Sequential admissions were sampled for necessary file information until the desired sample was attained.

The outcome (dependent) variable was treatment readiness scores, and there were six major predictor (independent) variables, namely, early onset, presence of a mental health disorder, number of problem behaviours, number of risk markers present, number

\footnotetext{
${ }^{2}$ Reference obtained from http://www2.chass.ncsu.edu/garson/PA765/regress.htm.
} 
of increases in the level of severity of antisocial behaviours, and presence of aggression. The relationship between treatment readiness scores and gender, age at admission, criminal history, and comorbidity of mental health disorders was also examined.

\section{Scoring the Predictor Variables}

The sections Client Demographics and Presenting Problems of the SCIS were used to collect information on all predictor variables. A manual with instructions was developed to code the data (Annex D). Information regarding the age of onset, frequency, severity, and setting of antisocial behaviours, as well as presence of aggression, mental health diagnoses, substance abuse problems, and criminal history are found under the Presenting Problems section of the SCIS.

Information regarding the age of onset of antisocial behaviours was coded using the items 'early onset (before age six)' (yes/no), 'stubborn (preschool onset)' (yes/no). This was used to determine if there is an onset of antisocial behaviours before the age of six, but also if the child displayed problems in the preschool years. Similarly, the frequency of antisocial behaviours prior to admission was determined using the item 'frequent antisocial acts' (yes/no), and the frequency in which these occur (the SCIS has six categories for this: 'less than once a month', 'once a month', '2-3 times in a 2 week period', '2-4 times a week', 'once to twice a day', '3 or more time a day'). For statistical purposes, the variable was recoded as 'once a week or more', '2-4 times in a week', 'everyday'. The item 'variety of antisocial behaviours' (yes/no) and 'variety of settings' (yes/no) was used to assess if the youth's antisocial behaviours are diverse and occur in one or several settings (home, school, community). Finally, the measure of aggression consisted of the following items: 'fighting (before age 12)' (yes/no), sexual aggression 
(sexual touching and assault)' (yes/no), and 'violence (adolescent onset, age 12 and above)' (yes/no). A 'yes' in any category indicated that the youth displayed aggressive behaviours.

\section{Composite Measure of Problem Behaviours.}

An index of antisocial behaviours was created by adding the number of problem behaviours marked as present for a total composite score. There were a total of 15 potential problem behaviours that were coded: substance abuse, stubbornness (before age 3), defiant, oppositional, authority avoidant (onset before or after age 12), minor covert behaviour, property damage before age 12 , property damage after age 12 , serious delinquency, bullying, fighting, violence, sexual acting out, sexual aggression, and suicide ideations, attempts or gestures.

Index of Increase in the Level of Severity of Antisocial Behaviours over Time.

Whether or not there was an increase in the level of severity of antisocial behaviours was measured by combining items in the SCIS that fit into the pathways model. For instance, in determining if there was an increase in the severity of nonaggressive behaviours, the items 'defiance before age 12' (yes/no), 'authority avoidant (before age 12)' (yes/no), 'minor covert behaviour (before age 12)' (yes/no) and 'property damage (before age 12)' (yes/no) were compared to 'oppositional after age 12' (yes/no), 'property damage (after age 12)' (yes/no) or 'serious delinquency (adolescent onset)' (yes/no). If an item was present in at least one 'before age 12' and one 'after age 12' category, the rater concluded that there was an increase in the severity of the youth's antisocial behaviours over time (yes/no). Exceptions to this involved when both items 
refer to the same behaviour (e.g., property damage before age 12 and property damage after age 12), in which the rater did not conclude that there was an increase in the severity of antisocial behaviours over time.

To determine if there was an increase in the severity of aggressive behaviours over time, the items 'bullying (before age 8)' (yes/no), 'fighting (before age 12)' (yes/no), and violence (adolescent onset)' (yes/no) were selected. Youth with the presence of only one of 'bullying (before age 8)' or 'fighting (before age 12) or 'violence (adolescent onset) received a score of ' 0 ', indicating no increase. Youth who progressed from 'bullying (before age 8)' or 'fighting (before age 12)' to 'violence (adolescent onset)', received a score of ' 1 ', indicating an increase in severity.

The extent to which there was an increase in their severity of sexually aggressive behaviours over time was measured using the items 'sexual acting out (solitary and interpersonal)' (yes/no), and sexual aggression (sexual touching to assault)' (yes/no). Coding procedures for the increase in severity of sexual aggressive behaviours are identical to that of the aggression-severity variable previously described. Another severity increment to consider is the progression from non-aggressive to aggressive behaviours. A variable was created so that if any one of the non-aggressive behaviours (before age 12) and 'violence (adolescent onset)' were present, the rater concluded there was an increase in the severity of antisocial behaviours over time. Severity groups were then created by calculating mean scores, that is, all items were added for a combined measure of increase in severity of antisocial behaviours. 
The variables early onset, frequency of antisocial behaviours, index of severity and multiple settings constitute the measure of risk, which is obtained by adding up the number of risk markers present for a total score.

\section{Other.}

Mental health disorders were coded using the item 'professional diagnosis'. First, it was determined whether or not the youth had previously received a professional diagnosis of a mental health disorder (yes/no). If more than one was selected, then the rater coded the youth as comorbid, and recorded the total number of professional mental health diagnoses. Demographic data such as gender and age were collected using the Client Demographic Information and Presenting Problems section of the SCIS (i.e., ‘chemical dependency' (yes/no), ‘suicidal ideations/gestures/attempts' (any one) (yes/no)). Criminal history was noted as present if the youth had been charged and convicted of a crime and was designated as a young offender (yes/no). Further details for scoring can be found in the coding manual. In case where there was information missing for the key predictor variables, attempts were made to verify the remainder of the file (i.e., other mental health evaluations) before removing the case from the study. If more than $10 \%$ of information is missing, then the case was excluded from the study.

\section{Scoring the Outcome Variable}

Information found on the CIF was used to score the TR:SV. To assist in rating the nine treatment readiness items (score ranging between ' 0 ' and ' 3 ' for each item), a behavioural description of each construct is provided in the TR:SV, along with specific indicators to be used to score the youth's response in the corresponding CIF item. 
Table 4 provides a list of the eight TR:SV items, and the corresponding CIF item used for scoring. For example, the CIF items 'please tell us why you think you are here' and 'what do you think your parents or guardians would list as your negatives' were used to provide a score for 'problem recognition'. The TR:SV manual provides a description of the construct (e.g., current appraisal of the situation, understanding and ownership of problems $)$ and provides indicator levels to score the item $(0=$ views the problem as solely the result of others or circumstances, $1=$ views the problem as mainly the result of others or circumstances, $2=$ views self as a part of the problem, or $3=$ views self as a major part of the problem). In order for the youth to receive a score of ' 3 ', they must have demonstrated on the CIF item that they understood the reasons why they had been admitted to Crisis, and had taken ownership of their problems. Without ownership, but with an understanding of the problem, youth who could identify reasons as to why they needed treatment were given a score of ' 2 '.

The remaining treatment readiness items were scored using this procedure, excluding the item 'treatment behaviours', which was measured using the Crisis Daily Log. Youth engaging in Crisis day activities and who followed rules and regulations (i.e., participates in group sessions, positive peer and staff interactions, completes homework) received a score or ' 3 '. If there was evidence of participation in treatment, but some resistance on the part of the youth, the score was reduced to a ' 2 '. Similarly, if there was evidence of participation in treatment but a lack of engagement (i.e., youth who disturb others or who do not participate in activities) then a score of ' 1 ' was given. 
Table 4

Treatment Readiness: Short Version (TR:SV and Corresponding Items from the Crisis Information Form (CIF) and the Crisis Daily Log

TR:SV Items

CIF and Crisis Daily Log Items

Problem Recognition (understanding and ownership of problems)

Benefits of Treatment

(considers short and long-term benefits)

Treatment Interest

(views about treatment)

Treatment Distress

(emotional distress towards treatment)

Treatment Goals

(awareness of skills and knowledge

required for treatment gain, sets

realistic goals)

Motivational Consistency

(expressions of motivations for treatment)

Treatment Support

(external support for changing)

Treatment Behaviours

(Positive and appropriate interaction with staff and peers, participation in group activities/homework)
Please tell us why you think you are here?

What do you think your parents or guardians would list as your negatives?

How do you think the staff at Crisis can help you and/or your family?

Have you ever received any counselling?

Would you like to speak to anyone with any concerns you may have?

What do you think needs to be worked on or changed at home (or the place you live)?

Tell me the positive things about yourself and the things you would like to change:

Would you consider your friends to be an important part of your life? How have they been able to help you through the difficult times?

Crisis Daily Log: recorded behaviours during 5-day stay at Crisis 
Finally, youth who showed a complete lack of engagement in treatment (i.e., treatment dropout, program expulsion) were given a score of ' 0 '. The TR:SV manual provides a more complete description of each item that was scored.

The item scores were then summed to provide a total readiness score, with a maximum possible value of ' 24 '. These scores were then categorized into levels as follows: low readiness (scores ranging between ' 0 ' and ' 7 '), moderate readiness (scores ranging between ' 8 ' and ' 15 '), or high readiness (scores ranging between '16' and ' 24 '). Interrater reliability was also assessed for treatment readiness scores because ratings are based on assumptions made by individual raters and these could differ in interpretation. A researcher who was blind to the expected outcome of the study was recruited and trained in conducting TR:SV assessments, and proceeded in coding 10 cases.

\section{Statistical Analyses}

\section{Data Screening and Descriptive Analyses}

Data was first subjected to data cleaning and screening. There was relatively no missing data, as cases were only selected if more than $90 \%$ of the SCIS was completed. In 110 of 115 cases, the SCIS was $100 \%$ complete.

Outliers have the potential to inflate error rates and decrease the validity of the coefficients for subsequent regression analyses. Frequency statistics, histograms and scatter plots will identify any outliers, determine if treatment readiness scores are normally distributed and if so, state the nature of the departure from normality (skewness, kurtosis). Basic descriptive statistics (e.g. frequencies, means) were also calculated to highlight the demographic and behavioural characteristics of the sample. 


\section{Reliability Analyses}

The internal consistency of the TR:SV was examined using Cronbach's alpha, a measure of level of mean inter-correlation. Furthermore, the extent to which there was agreement amongst the raters for overall treatment readiness scores and individual treatment readiness items was examined using weighted kappa coefficients. A value of .70 or higher indicates high agreement amongst raters (that agreement is better than chance). High interrater reliability also provides evidence for the reliability of the TR:SV using case file information.

\section{Group Differences}

Analysis of variance was used to determine if group differences exist between mean treatment readiness scores and gender (males versus females), onset of antisocial behaviours (early versus late), aggression (aggressive versus non-aggressive), age at admission (older versus younger), and mental health disorders (professional diagnosis versus no professional diagnosis). Post-hoc analyses (Tukey HSD) were performed with variables of three groups or more to determine where significant differences exist.

\section{Correlation Matrices}

Bivariate correlations (Pearson $r$ ) were conducted to determine the degree of association between treatment readiness scores and all predictor variables. Correlation coefficients indicate the degree to which variation in the predictor variables is related to variation in treatment readiness scores, and also show the direction of this relationship. Coefficients above .70 signify a strong relationship between the predictor variable and treatment readiness scores. 
While stepwise regression uses a meaningful criterion for selecting variables, it does not assure that the selected variables will not display high multicollinearity. High multicollinearity can lead to an increase in the standard errors of the regression coefficients, difficulties in assessing the individual importance of each predictor, reduced size of R-squared values, and increased possibility of making Type II errors. A Pearson correlation matrix for all the predictor variables in the model, as well as collinearity diagnostics were conducted to determine if there is intercorrelation amongst the predictor variables such that their effects cannot be separated. If any two predictors were highly correlated ( .80 or higher), then the order of entry of variables into the regression model was controlled for. If the problem cannot be eliminated, then the most intercorrelated variables can be removed or the common variance can be treated and analyzed as a separate variable.

\section{Multiple Regression Analyses}

Prior to conducting regression analyses, all categorical variables with three or more levels were recoded into dummy (binary variables, using ' 0 ' and ' 1 '). The slope now represents the estimated average change in $Y$ when differentiating between one group and the other, whereas the intercept represents the estimated average value of $Y$ for the group coded as ' 0 '.

Multiple stepwise regressions were conducted to determine the contribution of specific behavioural characteristics of antisocial youth to low treatment readiness. This method of analysis was used because it allows for the measure of the relationship between the criterion variable and specific predictor variables, while controlling for confounding factors (e.g., gender, age). Furthermore, it is a good measure to use for 
exploratory model building. The analytical procedure in forward regression is based on the contribution of each variable to the explained variance of the criterion variable. It involves selecting the most correlated predictor variables first (the $x l$ variable with the highest simple correlation with $Y$ ), and adding other predictor variables which most correlates with the remaining variance in treatment readiness, until selection of an additional predictor variable no longer increases the $R^{2}$ value by a significant amount. A criterion of .05 was used for entering variables into the regression models. This method therefore isolates specific predictor variables and produces the best equation with as few terms as possible.

\section{Results}

\section{Data Clean-Up and Normal Distribution}

A preliminary check on data quality using frequency analyses was conducted to identify gross data errors and extreme outliers. Several box plots and histograms were also drawn to identify any outliers and to determine if the data are normally distributed. No potential outliers were found that could be categorized as extreme observations. Treatment readiness scores were slightly skewed, but reasonably normal. Scores were neither centered up at the ceiling or at floor of the scale as to restrict variations and have an effect on correlations. Normal probability plots of the quantitative independent variables (e.g., index of severity and number of mental health disorders) were drawn and show that these data are also symmetrical and normally distributed.

Treatment readiness levels (low, medium, high) however were highly skewed, and were reorganized based on the mean and standard deviation of overall treatment readiness scores. Those who scored three standard deviations above the mean were 
placed in the high readiness group, and those who scored three standard deviations below the mean were placed in the low readiness group. Those who scored somewhere in between were labelled the moderate readiness group.

\section{Adolescent Characteristics}

Frequencies and means were conducted to highlight sample characteristics. The results are displayed in Table 5, and show that slightly more than half of the sample is composed of girls (54\%), and that the mean age of the sample at the time of admission to the RSC was 13.82 years. Of particular note, $40 \%$ of youth in the sample have been professionally diagnosed with a mental health disorder, and $24 \%$ of these include more than one diagnosis (comorbidity).

Frequencies for problem behaviours from age three to present are shown in Table 6. Results indicate that the most prevalent behavioural problems within this sample include stubbornness (preschool onset) (70\%), minor covert behaviour (before age 12) (67\%), defiance (before age 12) (63\%), and authority avoidance (adolescent onset) (59\%). There was also a high prevalence of substance abuse problems (52\%), and suicidal ideations, gesture or attempts (48\%). Adolescent onsets of more serious forms of antisocial behaviours such as serious delinquency (robbery, fraud), and violence were less frequent ( $22 \%$ and $26 \%$, respectively). However, $47 \%$ of youth have previously displayed some form of aggressive behaviour, including bullying before eight years of age $(32 \%)$. 
Table 5

Sample Characteristics $(N=115)$

Characteristics

$\%(n)$

$M$

$S D$

Mean age

13.82

1.27

Gender

Boys

$46 \%(54)$

Girls

$54 \%(46)$

Legal guardianship: lives with parents

$91 \%(105)$

Criminal history

$8 \%(9)$

Mental health disorders

Diagnosis of a mental health disorder

$40 \%(46)$

Comorbidity

$24 \%(10)$

Table 7 provides the percentage of risk markers for the continuity of antisocial behaviour that are present for each youth, as defined by Loeber and colleagues. Overall, $42 \%$ of youth had three or more risk markers present. An early onset of problem behaviours (before the age of six) was present in $43 \%$ of the sample, and a late onset of antisocial behaviours (age 12 and above) was present in $11 \%$ of the sample. The vast majority of youth in this sample displayed frequent antisocial behaviours (92\%), in multiple settings (90\%). An increase in the level of severity of antisocial behaviours was also common for many youth within this sample, especially within the non-aggressive behaviour category $(60 \%)$. 
Table 6

Index of Problem Behaviours: Descriptive Statistics $(N=115)$

\begin{tabular}{|c|c|c|c|}
\hline Characteristics & Present & $n$ & $M$ \\
\hline Mean number of problem behaviours & & & $6.23^{1}$ \\
\hline Boys & & & 6.49 \\
\hline Girls & & & 6.00 \\
\hline Stubborn (preschool onset) & $70 \%$ & 80 & \\
\hline Minor covert behaviour (before age 12 ) & $67 \%$ & 77 & \\
\hline Defiance (before age 12) & $63 \%$ & 72 & \\
\hline Oppositional (after age 12) & $52 \%$ & 56 & \\
\hline Authority avoidant (before age 12 ) & $34 \%$ & 39 & \\
\hline Authority avoidant (adolescent onset) & $59 \%$ & 63 & \\
\hline Property damage (before age 12) & $26 \%$ & 30 & \\
\hline Property damage (after age 12) & $44 \%$ & 47 & \\
\hline Serious delinquency (adolescent onset) & $22 \%$ & 23 & \\
\hline Substance abuse problems & $52 \%$ & 59 & \\
\hline Aggressive & $47 \%$ & 54 & \\
\hline Bullying (before age 8) & $32 \%$ & 37 & \\
\hline Fighting (before age 12) & $29 \%$ & 33 & \\
\hline Violence (adolescent onset) & $26 \%$ & 28 & \\
\hline Sexual acting out & $11 \%$ & 13 & \\
\hline Sexual aggression & $3 \%$ & 4 & \\
\hline Suicidal ideations, gestures or attempts & $48 \%$ & 55 & \\
\hline
\end{tabular}


Table 7

Risk Markers: Early Onset, Frequency, Severity and Multiple Settings $(N=115)$

Risk Markers

One risk marker present

Two risk markers present

Three risk markers present

Four risk markers present

Onset

Early onset (before age 6)

Childhood onset (age 6 to 11)

Adolescent onset (age 12 and above)

Frequent antisocial behaviours

Once a week or less

2-4 times in a week

Everyday

Increase in level of severity of antisocial behaviours ${ }^{1}$ $70 \%(76)$

Increase in severity of non-aggressive behaviours $60 \%(69)$

Increase in severity from non-aggressive to aggressive $24 \%(27)$

Increase in severity of aggressive behaviours $12 \%(14)$

Increase in severity of sexually-aggressive behaviours $3 \%(3)$

Presence of antisocial behaviours in multiple settings $90 \%(103)$

\footnotetext{
Index of severity: $M=1.49, S D=.74$.
}

Finally, information regarding treatment readiness scores is described in Table 8. Scores obtained range between two and 20 (the maximum possible value was 24 ), with the mean situated at $8.24(S D=3.80)$. This indicates that on average, scores were in the 
Table 8

TR:SV Mean Item Scores $(N=115)$

Item

$\%(n)$

$M$

$S D$

Mean treatment readiness score

Adjusted treatment readiness group levels

Low (0-4)

Medium (5-11)

High (12 and above)
$15 \%$ (17)

$68 \%(78)$

$17 \%(20)$

Mean readiness item scores ${ }^{2}$

Problem recognition

Benefits of treatment

.50 .78

Treatment interest

Treatment distress

Treatment goals

Treatment behaviours

Motivational consistency

Treatment support

Tinimum score $=2$, maximum score $=20 .{ }^{2}$ Minimum score $=0$, maximum score $=3$.

moderate range of treatment readiness ${ }^{3}$. The youth in this sample scored higher on the items 'treatment behaviours' ( $M=1.50, S D=.67)$, and 'problem recognition' $(M=1.38$, $S D=.76)$, and lower on the items 'treatment distress' $(M=.50, S D=.79)$ and 'benefits of treatment' $(M=.50, S D=.87)$. These numbers indicate that on average, youth had somewhat acknowledged the reason why they had been admitted to a closed-custody facility, but for the most part, thought they were not at fault, and felt no distress over the need to seek help and understand what could be gained out of receiving help. As one

\footnotetext{
${ }^{3}$ Following transformations on the 'treatment readiness level' variable, with scores ranging from 0 to 3 .
} 
youth interestingly wrote when asked "please tell us why you think you are here?", “because I run away all the time, but it's my parent's fault that I run away". At intake, only $10 \%$ of youth completely denied their problems, but an overwhelming $66 \%$ were not optimistic about being helped. However, during their stay at Crisis, only $6 \%$ showed poor rule compliance and low cooperation (treatment behaviours), and it could be argued that social desirability may have been a factor.

\section{Reliability Analyses}

Two types of reliability analyses were conducted for the present study. The internal consistency of the TR:SV was examined to obtain information about the relationship between individual readiness items and overall scores. Cronbach's alpha, a measure of level of mean inter-correlation, provided very good estimates of internal consistency $(\alpha=.78$ ), with item-total correlation coefficients ranging from .50 to .71 . Higher alphas indicate that random errors are potentially low, within-subject responses are consistent with one another, variability between subjects is higher, and variances are equal. As shown in Table 9, motivational consistency appears to be most related to treatment readiness $(r=.71)$, followed by treatment distress $(r=.68)$ and perceiving the benefits of treatment $(r=.67)$. Item-total correlations indicate how closely the items within a scale relate to the scale as a whole (how aggregating these items into a score is indicative of the construct of treatment readiness). Because low item-total correlations increase the standard error of measurement, they should potentially be removed from a scale. The variable 'treatment behaviours', with an item-total correlation of .50 , could potentially be dropped without affecting the TR:SV's overall internal consistency. Cronbach alphas were re-examined for all remaining variables with that item dropped. 
Table 9

TR:SV: Item-Total Correlations

Item

$r$

Problem Recognition

$.60 * *$

Benefits of Treatment

$.67 * *$

Treatment Interest

$.63^{* *}$

Treatment Distress

$.68^{* *}$

Treatment Goals

$.61 * *$

Treatment Behaviours

$.50 * *$

Motivational Consistency

$.71 * *$

Treatment Support

$.63^{* *}$

$* * p<.01$

In fact, the variable could be removed while maintaining the same level of internal consistency and minimizing the contribution of random error to readiness scores. However, because this study is conducting preliminary research and because the correlation is not substantially low, the variable was kept in the TR:SV for the analyses. Interrater reliability estimates for treatment readiness scores were also obtained by using Cohen's Kappa. This measure determines the extent of consensus when scoring items on the TR:SV, and thus ensures homogeneity on the basis of which decisions are made in regard to treatment readiness. This type of reliability analysis is also important when clinical judgment is part of the rating process because it produces a measure of agreement between two raters. As shown in Table 10, kappas for each item on the TR:SV ranged between .66 and .85 , demonstrating good interrater reliability. It is important to note however that these estimates were based on a small number of cases $(n=10)$. 
Table 10

TR:SV Interrater Reliability

Item

Kappa

Problem Recognition

$.80 * *$

Benefits of Treatment

$.80 * *$

Treatment Interest

$.68 * *$

Treatment Distress

$.66 * *$

Treatment Goals

$.85^{* *}$

Treatment Behaviours

$.71 * *$

Motivational Consistency

$.70 * *$

Treatment Support

$.84 * *$

** $p<.01$

\section{Group Differences}

All findings described here and in future sections are statistically significant at least at the $p<.05$ level unless otherwise noted. For descriptive purposes, differences were examined across a variety of variables. Gender differences were found for 'diagnosis of a mental health disorder' $\left(\chi^{2}(1,115)=3.36, p<.05\right)$, showing that approximately $50 \%$ of boys, compared to $32 \%$ of girls had been previously diagnosed with at least one mental health disorder, and that boys (15\%) were more likely than girls $(3 \%)$ to have been diagnosed with two or more mental health disorders $\left(\chi^{2}(1,115)=\right.$ $5.07, p<.05)$. There was no evidence of gender differences for an early onset of antisocial behaviours ( $49 \%$ of boys compared to $37 \%$ of girls, $\chi^{2}(1,115)=1.67, p=$ .14 ), aggression $\left(51 \%\right.$ of boys compared to $49 \%$ of girls, $\left.\chi^{2}(1,115)=1.04, p=.20\right)$, and 
number of risk markers $\left(46 \%\right.$ of boys compared to $54 \%$ of girls, $\chi^{2}(3,115)=3.70, p=$ .29). Furthermore, no significant age differences were found for any of the variables, however, these results must be interpreted with caution, as there was little variability within this variable (the sample was between the ages of 10 and 16).

Of those who had an onset after the age of six, $71 \%$ had never been diagnosed with a mental health disorder, whereas $55 \%$ of youth with an onset before the age of six had been diagnosed with a mental health disorder $\left(\chi^{2}(1,115)=8.11, p<.01\right)$. Not surprisingly, $77 \%$ of youth with a criminal history had an onset of antisocial behaviours before the age of $\operatorname{six}\left(\chi^{2}(1,115)=4.93, p<.05\right)$. Aggressive youth were slightly more likely than non-aggressive youth to have had an onset of antisocial behaviours before the age of six (47\% versus $38 \%$, relatively), but this relationship was not statistically significant $\left(\chi^{2}(1,115)=1.05, p=.20\right)$.

Significant gender differences were found in mean TR:SV scores $(F(1,113)=$ 4.03, $p=.05)$, demonstrating that girls $(M=8.89, S D=3.89)$, on average, scored slightly higher on treatment readiness compared to boys $(M=7.49, S D=3.50)$. It is not surprising that there was a significant difference $(F(1,113)=5.15, p=.03)$ in the mean readiness scores of youth with a criminal history $(M=5.56, S D=3.12)$ compared to those with no criminal history $(M=8.47, S D=3.74)$. Age did not appear to have an influence on readiness scores. That is, the younger youth within the sample were equally likely to score low in treatment readiness than the older youth. However, it should be noted that the largest non-significant difference in readiness scores was found between youth who were 10 years $(M=5.50)$ and 15 years of age $(M=8.58)$. 
As hypothesized, the mean treatment readiness scores of youth with an early onset of problem behaviours (before the age of six) were significantly lower $(M=7.27, S D=$ 3.70) than youth with a later onset of problem behaviours $(M=9.69, S D=2.84)(F(2$, $112)=3.31, p<.05$ ). This is a key finding given that an early onset of antisocial behaviours appears to be associated with all facets of the continuity of antisocial behaviours, including criminal behaviours.

When the nature and complexity of mental health diagnoses were examined, several important findings also emerged. The mean readiness scores of youth who have been professionally diagnosed with a mental health disorder (regardless of type) were lower $(M=7.30, S D=3.17)$ compared to youth who have not been diagnosed with any mental health disorder $(M=8.87, S D=3.96)(F(1,113)=4.93, p=.03)$, and much lower for those who have been diagnosed with two or more disorders $(M=5.80, S D=2.53)$ $(F(1,113)=4.76, p=.03)$. Subsequent analyses obtained by selecting only those cases in which a diagnosis of a mental health disorder was present determined that the mean treatment scores of youth with a diagnosis of Attention Deficit Hyperactivity Disorder (ADHD) $(M=6.82, S D=2.97)$ were significantly lower than youth with any other type of diagnosis $(M=8.82, S D=3.91)(F(1,113)=6.98, p=.009)$. It is important to note that no significant group differences were found between aggressive and non-aggressive youth, disconfirming the hypothesis that aggressive youth will differ significantly from non-aggressive youth in treatment readiness scores.

\section{Correlations}

Prior to conducting regression analyses, it was necessary to determine if any of the predictor variables were significantly correlated with the outcome variable (Table 11). 
Pearson product moment correlations were conducted, and showed that treatment readiness scores were moderately correlated with gender $(r=.19, p<.05)$, early onset $(r$ $=.23, p<.05)$, diagnosis of a mental health disorder $(r=.34,, p<.05)$, comorbidity of mental health disorders $(r=.20, p<.05)$, and criminal history $(r=.21, p<.05)$. Contrary to predictions, the index of problem behaviours (including each individual item), index of severity of antisocial behaviours, number of risk markers present, and aggression type were unrelated to treatment readiness scores. These findings are important for several reasons. First, they confirm the hypothesis that treatment readiness scores will be negatively related to the number of mental health diagnoses, and also provide information regarding the importance that exploratory variables may have in predicting low treatment readiness. However, these findings also provide some evidence that certain predictor variables identified in the literature as potential impediments to treatment readiness may not predict scores on the TR:SV, and therefore, may need to be removed from the regression model.

Correlations between predictor variables and individuals items on the TR:SV were also examined for exploratory purposes. Interestingly, an early onset of antisocial behaviours was moderately associated with problem recognition $(r=.21, p<.05)$ and treatment interest scores $(r=.24, p<.05)$. That is, youth with a later onset of problem behaviours were somewhat more likely to acknowledge their problems and to express an interest in treatment, and as a result, scored higher on these items than youth with an earlier onset of problem behaviours. Furthermore, the variable 'criminal history' was also correlated with problem recognition scores $(r=.21, p<.05)$. 
Table 11

Pearson Product-Moment Correlations ( $r$ ) between Predictor Variables and Treatment Readiness Scores

Predictors

$r$

Age at admission

.57

Gender

$.19 *$

Early onset

$.23^{* *}$

Aggressive pathway

.01

Criminal history

$.21^{*}$

Diagnosis of a mental health disorder

$.27 * *$

Comorbidity of mental health disorders

$.20 *$

Number of risk markers

$-.13$

Index of problem behaviours

$-.10$

Index of increase in the level of severity

$-.07$

$* p<.05 . * * p<.01$

Gender differences were also found, with evidence showing that scores for social support were higher for girls than boys ( $r=.37, p<.001)$. It was noted that $21 \%$ of the sample indicated having no social support, and that four out five of these youth were boys. Treatment behaviours were moderately correlated with having a criminal history ( $r$ $=.27, p<.01)$, diagnosis of a mental health disorder $(r=.27, p<.01)$, and number of risk markers $(r=-.21, p<.05)$. It is also interesting to note that treatment goals were less well-articulated by youth with a diagnosis of a mental health disorder $(r=.21, p<.01)$, however, ADHD youth $(r=.34, p<.001)$ were more susceptible. Finally, motivational consistency scores were negatively correlated with an increase in the level of severity of 
antisocial behaviours $(r=-.24, p<.001)$, demonstrating that higher scores on this index were associated with lower motivation for treatment.

\section{Multiple Regression Analyses}

It is important to determine to what extent the predictor variables are correlated with one another to eliminate the possibility of multicollinearity. Pearson product moment correlations were conducted for all predictor variables, and range between .06 and .66 (Table 12). As previously mentioned, any correlation amongst predictor variables of .80 or higher warrants further investigation. These findings indicate that while some variables are moderately correlated with one another, they are not correlated to the extent that one would question the distinctiveness of these constructs. Multicollinearity diagnostics in the regression analyses also confirmed these results.

Based on the literature and the correlation results, forward regression analyses were performed to determine the contribution of each of the predictor variables to the prediction of overall treatment readiness scores. Model 1 involved entering the variables identified by the literature as potential predictors of treatment readiness, which includes: number of risk markers, diagnosis of a mental health disorder, aggressiveness, and index of problem behaviours. Model 2 involved entering these same variables while controlling for gender and age at admission (by forcing these variables into the regression model using the 'enter' method). Results show that in model 1, the overall $R$ was significant $(R=.20 ; p<.05)$, but only one variable significantly added to the overall prediction of treatment readiness scores, namely, diagnosis of a mental health disorder $(\beta$ $=-.20, t(110)=-2.22, p<.05)$. 
Table 12

Pearson Product-Moment Correlations (r) Between Predictor Variables

\begin{tabular}{|c|c|c|c|c|c|c|}
\hline $\begin{array}{l}\text { Predictor } \\
\text { Variables }\end{array}$ & $\begin{array}{c}\text { Mental } \\
\text { Health } \\
\text { Disorder }\end{array}$ & $\begin{array}{l}\text { Early } \\
\text { Onset }\end{array}$ & $\begin{array}{l}\text { Aggress } \\
\text {-ion }\end{array}$ & $\begin{array}{l}\text { Problem } \\
\text { Behaviour }\end{array}$ & Severity & $\begin{array}{c}\text { Risk } \\
\text { Markers }\end{array}$ \\
\hline $\begin{array}{l}\text { Mental Health } \\
\text { Disorder }\end{array}$ & & $.27 * *$ & -.06 & .17 & -.08 & $.22 *$ \\
\hline Early Onset & $.27 * *$ & & .11 & $.27 * *$ & .04 & $.66^{* *}$ \\
\hline Aggression & -.06 & .11 & & $.50 * *$ & $.63^{* *}$ & .15 \\
\hline $\begin{array}{l}\text { Problem } \\
\text { Behaviours }\end{array}$ & .17 & $.27 * *$ & $.50 * *$ & & $.41 * *$ & $.43 * *$ \\
\hline Severity & -.08 & .04 & $.63 * *$ & $.41 * *$ & & .15 \\
\hline Risk Markers & $.22 *$ & $.66^{*}$ & .15 & $.43 * *$ & .15 & \\
\hline
\end{tabular}

In model 2, when gender and age were controlled for, the overall $R$ was greater in magnitude $(R=.27 ; p<.05)$, and having a diagnosis of a mental health disorder was slightly correlated with treatment readiness scores $(\beta=-.19, t(108)=-2.04, p<.05)$.

This study found a moderate relation between early onset and treatment readiness scores. It can be argued that an early onset may be the most important of the four markers for the continuity of antisocial behaviours. For these reasons, and because the variables that make up the measure of risk markers contain little variability within two of the four constructs (frequency and multiple settings), the same regression analyses were conducted by replacing the variable 'risk markers' by 'early onset'. In this model, results show that the overall $R$ was significant $(R=.27 ; p<.05)$ and greater in magnitude as compared to the $R$ obtained in models 1 and 2 . An early onset of antisocial behaviours 
was the best predictor of treatment readiness scores $(\beta=-.27, t(110)=-2.38, p<.05)$. When gender and age were controlled for, the overall $R$ was even greater in magnitude ( $R$ $=.31 ; p<.05)$. Early onset significantly contributed to the prediction of treatment readiness scores $(\beta=-.25, t(108)=-2.20, p<.05)$, and explained $10 \%$ of its variance $\left(R^{2}\right.$ $=.10, F(3,75)=2.85, p<.05)$.

A final exploratory regression was performed with only the variables that significantly correlated with treatment readiness scores (diagnosis of a mental health disorder, early onset, gender and criminal history). It is important to note however that these correlations were moderate in nature, ranging from .19 to .27 . This combination model yielded a significant regression analysis $(R=.23 ; p<.05)$, again showing that the best model for the prediction of treatment readiness scores is an early onset of antisocial behaviours $(\beta=-.23, t(110)=-2.45, p<.05)$.

\section{Discussion}

This study aimed at building on the emerging efforts of identifying the predictors of treatment readiness in antisocial youth. Theoretical and exploratory in nature, this study is one of few to expand on the number of variables investigated in relation to treatment readiness, such as an early onset of antisocial behaviours, the frequency and severity of antisocial behaviours, aggression, and the prevalence of mental health disorders. The importance of identifying these youth has been demonstrated by a number of studies that have shown that the assessment of readiness is relevant to the effective delivery of treatment, to successful treatment outcomes, and ultimately, desistance from delinquent behaviours. 
On average, the youth in this study were in the low to moderate range of treatment readiness, and girls were more likely than boys to score within the higher range. This was expected given that girls in this study had a later onset of antisocial behaviours than boys, a finding that is supported by previous research (see Fergusson et al., 2000). Furthermore, the adult correctional treatment literature has shown that on average, women have higher treatment readiness scores prior to, and after treatment, and have gained greater benefits from treatment as compared to men (Serin, Kennedy, \& Mailloux, 2005). The findings from this study also provide additional evidence for the fact that boys may be more likely than girls to require readiness assessments and targetedreadiness interventions. Whether it is the impact of cognitive, behavioural or social factors is not yet understood. However, this study found that amongst the items of the TR:SV, social support was the only measure in which gender differences were found, with girls scoring on average significantly higher than boys. On several occasions, girls wrote that "my friends help me stay out of trouble", or "my friends stop me from doing drugs". The study by Gorske et al. (2003) was one of few with a sample that consisted predominantly of female antisocial youth, and found that family support in treatment was a key component of successful discharges. Thus, strong social support may be an important readiness factor requiring further analysis. Although stronger social networks are most often associated with girls, it is necessary to determine if its relation to treatment readiness is specific to gender.

Perhaps the most relevant finding of the present study was that the best correlates of treatment readiness were early onset and diagnosis of a mental health disorder. It was also found that youth with a criminal history compared to other delinquent youth were 
particularly likely to have had an early onset of antisocial behaviours and low treatment readiness scores. These findings are consistent with that of Leistico and Salekin (2003), and concurrently confirm several hypotheses of this study. However, when these predictors were combined into various regression models, early onset was the only variable that significantly contributed to the prediction of readiness scores. These findings are notable because they add to a body of literature that states that an early onset of behavioural problems is related to a variety of outcomes including the continuity of antisocial behaviours and decreased desistance. Research in this area has confirmed on several occasions that early onset youth are less likely to respond to treatment, and are less likely to desist in engaging in delinquent behaviours (Gorske et al., 2003; Leistico \& Salekin, 2003; Loeber, 1991).

The literature has shown that youth who have serious and persistent antisocial problems are less likely to be ready for treatment. The current study did not find a significant relationship between treatment readiness and the number of problem behaviours, the number of risk markers present, and aggression. In contrast with the findings of Leistico and Salekin (2003), this study did not find that youth who were low on treatment readiness were more likely to have committed more serious antisocial acts. It should be noted however that there was a moderate relationship between the level of severity and motivational consistency. The higher the index of severity (as identified by the number of categories in which there was presence of an increase in the level of severity of antisocial behaviours), the lower the motivational consistency score. Given that severe and persistent antisocial behaviours have been linked to early behavioural problems and low treatment readiness in several studies (for example, see Gorske et al. 
2003; Leistico \& Salekin, 2003; Williamson et al., 2003), the disparity between these findings should interpreted with caution.

Currently, there are no firm conclusions regarding the relationship between aggression and treatment readiness. Both the studies conducted by Leistico and Salekin (2003) and Williamson et al. (2003) have shown that even though violence is related to low treatment readiness, both aggressive and non-aggressive offenders were likely to score in the lower levels. This study also did not find that aggressive youth were more likely than non-aggressive youth to score low on treatment readiness. There were no differences in the mean treatment readiness scores of youth with an adolescent onset of violent behaviours compared to all other youth. In contrast with the theories and research of Loeber (1991) and Moffitt et al. (1996), this study found that early onset and later onset youths were equally likely to engage in aggressive behaviours.

Second, although the measures of severity and risk markers that were created for the purpose of this study did not produce significant results, its relationship with treatment readiness should be further examined. Leistico and Salekin (2003), Loeber (1991), and Moffit et al. (1996) amongst other researchers report that frequent and severe antisocial behaviours is a contributing factor to low treatment readiness/amenability. As previously described, the vast majority of youth in this study displayed frequent and severe antisocial behaviours in multiple settings, which provided the variable 'risk marker' with little variability. It is possible that these factors did not differentiate youth according to treatment readiness levels because this symptom is widespread within this population, but further research is needed to confirm these results. The remaining factor amongst the risk markers was early onset, and when regressed against other potential 
predictors of treatment readiness such as mental health disorders, was in fact the best predictor.

Finally, the index of problem behaviours was a composite measure of the number of the different varieties of problem behaviours present in each youth. The absence of a relationship with treatment readiness may signify that being antisocial in a variety ways does not necessarily affect readiness; it is not necessarily the type of behaviour itself but the underlying issues that lead to the antisocial behaviour. In fact, when each item on the index of problem behaviour was examined individually, no significant correlations were found with treatment readiness scores. Keeping in mind that there are correlations between low treatment readiness and an early onset of antisocial behaviours, a diagnosis of a mental health disorder, a past criminal history and gender, it is likely that other factors, perhaps dynamic in nature, should also be examined.

The literature states that antisocial youth are unmotivated to change because they often do not understand the need for treatment or cannot perceive the potential benefits of treatment (Breda \& Heflinger, 2004; Carlson et al., DeLeon et al., 1994; 1994; Gorske, Srebalus, \& Walls, 2003; Russell, 2005). Some researchers have reported that older youth are more likely to have acquired certain cognitive abilities needed to benefit from treatment (Leistico \& Salekin, 2003; O’Leary and Monti, 2004). Carlson et al. (1994) found that treatment amenability was associated with older youth who showed greater rule compliance and fewer problem behaviours. Interestingly, other researchers such Loeber (1991) argue that treatment readiness is highest amongst younger youth, because as the age of the child and the frequency and severity of their antisocial behaviours increases, malleability to treatment subsequently decreases. The results of this study do 
not provide support for these findings, and show that age is not a factor that could differentiate those with lower or higher readiness scores. Youth between the ages of 10 and 12 were equally likely to score low on readiness than youth who were who were between the ages of 13 and 15 . Other researchers also come to similar conclusions. Treatment retention in Russell's (2005) study was associated with dynamic factors such as cognitive skills, rather than static factors such as age. On a similar note, Breda and Heflinger (2004) did not find that age was related to treatment readiness; rather, it was the number of negative consequences experienced as a result of their behaviour and their perception of the necessity for treatment. Finally, in the study conducted by Leistico and Salekin (2003), intelligence and academic achievement correlated with treatment amenability.

This study found some evidence that the level of cognitive maturity or abilities acquired is relevant to treatment readiness, and may be influenced by an early onset of antisocial behaviours and the presence of a mental health disorder. Results showed that an early onset was significantly associated with problem recognition skills and treatment interest. These youth appear less likely to have the ability to engage in analytic problem solving (e.g., understanding and owning to their problems). The presence of a mental health disorder and the type of mental health disorder were especially relevant. The readiness scores of youth with an $\mathrm{ADHD}$ diagnosis were significantly lower than that of youth with any other type of mental health diagnosis, and when this relationship was examined in further detail, it was found that ADHD youth differed in their ability to articulate potential treatment goals and to show positive peer and staff interactions during their stay at the Crisis centre. 
The findings in the literature provide support for these results. Both Kann and Hanna (2000), and Kazdin (1993) report that the number of mental health disorders is related to low motivation for treatment in older youth with an early onset of antisocial behaviours. In addition, studies have shown that many early onset youth do not acquire the necessary cognitive skills needed to respond to difficult situations in a prosocial manner (Donnellan, Ge, \& Wenk, 2000; Leistico \& Salekin, 2003; Moffitt et al., 1996). Thus, readiness for treatment implies having acquired a certain level of cognitive maturity in order to maximize from the potential benefits of treatment.

As previously mentioned, this study found a correlation between treatment readiness and past criminal behaviour. Although this was a historical variable, this relationship underlines the importance of assessing criminogenic needs in relation to readiness. Carlson et al. (1994) have shown that certain dynamic constructs including criminogenic needs may better identify those requiring readiness-related assessments and treatment. In the current study, not all early onset youth have a past criminal history, but the vast majority of youth with a criminal history have an early onset of antisocial behaviours.

The recurring relation between the age when behavioural problems emerge and other factors related to delinquency may provide support for Moffit's et al.'s (1996) theory regarding the role of neurocognitive impairment in delinquent behaviours. This is may be the case for the current study, as early onset was defined as behaviours occurring before the age of six. Evidently, the identification and assessment of treatment readiness remains a complex issue requiring further analysis. Although the basis for the current 
study is theoretically grounded, the results also suggest that other factors not evaluated by the present study may also play a significant role in the prediction of treatment readiness.

\section{Study Limitations, Implications and Future Research}

The limitations of the present study are as follows: use of a retrospective design and self-report questionnaire to score TR:SV items, use of non-standardized indices of behaviours, potential for response-bias, small sample size, and absence of follow-up data. The most important of these limitations are related to its methodological shortcomings. Although the TR:SV has strong internal validity and interrater reliability, the limited number of significant results may have been compromised by the use of case file information, because the instrument was designed for face-to-face interviews. The CIF and the Crisis Daily Log were used to interpret and score the TR:SV, as the goal was to determine if level of readiness can be determined by self-report information. The CIF was the best measure to use as individual items could be matched to a TR:SV item, with the exception of 'treatment behaviours', for which information was captured using a daily $\log$ of behaviours. Furthermore, because the indices of problem behaviour and of severity created for the purpose of this study were theoretically-based, it is possible that different results could potentially have been obtained if standardized measures of antisocial behaviours had been used (although these were unavailable in the case files). Further research examining the potential utility of self-report information is necessary to confirm these findings. In addition, because this study is the first to use the TR:SV in a sample of antisocial youth, future studies should also be conducted using face-to-face interviews, or using multiple methods of data collection to and comparing the findings. 
Another limitation in the study is that it is not known if treatment readiness scores have been influenced by response bias. Self-report information on the CIF may potentially reflect to a certain extent an attempt by the youth to portray him or herself in a favourable manner. Efforts should be made to determine if the scores on the TR:SV are influenced by social desirability, whether through self-report or face-to-face methods of data collection. Other limitations of this study include small sample size and absence of follow-up data. Cross-validation studies are needed with larger sample sizes to determine if more significant results can be obtained, and if they can be generalized across different samples of antisocial youth. Moreover, because the TR:SV constitutes part of a measure of change within the TRRG:SV, post-readiness data are also required to evaluate treatment gains. This type of research is important because it will allow researchers to determine the extent to which those who were low on readiness prior to treatment are more or less likely to gain from treatment intervention.

It was the goal of this study to obtain information that can be used in future studies using comparison groups (e.g., readiness-training activities versus control group) in which cases are assigned at random and measures of treatment gains are also obtained. Because treatment readiness in antisocial youth is a relatively new area of research and significant findings in the current study are limited to a few selected predictors of treatment readiness, it is recommended that studies using experimental designs should not be realized until further descriptive research has been conducted.

The following includes potential research considerations for examining treatment readiness in antisocial and delinquent youth. First, research is required that will examine readiness scores and treatment outcomes using multiple assessments of readiness (e.g., 
TR:SV, RST-i). Furthermore, the psychometric properties (e.g., internal consistency, interrater reliability) of these assessments could also be compared. This research is needed to determine which assessments are most applicable in juvenile clinical settings.

The exact relationship between the index of severity and TR:SV scores is lacking significant empirical support in the current study and should be further examined to determine if the findings were the result of issues with the non-standardized scale of the level of increase in the severity of antisocial behaviours. It appears that early onset, on its own or coupled with a mental health disorder, reduces treatment readiness. However, additional research exploring these specific features is needed to advance our understanding and clarify the exact nature of these relationships. The evidence for the potential applicability of dynamic constructs suggests that it may be important to determine how youth can be identified according to deficiencies in cognitive skills and academic achievement. Future research should study this issue in further detail, especially in relation to early onset, to determine if these factors may provide a better indication as to who is less likely to be ready for treatment. In this manner, we may begin to shed more light on the ambivalence that youth have in regard to treatment engagement.

Other static and dynamic factors that appear worthy of further investigation include the symptoms and types of mental health disorders, and the influence of protective factors (e.g., social support). Further research can also be conducted to examine the complex relationship between aggression and treatment readiness. Finally, the relationship between early onset and treatment readiness using a higher threshold of onset (e.g., age 7 or 8 ) should also be investigated. This can determine if treatment 
readiness is related to a specific age of onset, thereby improving the differentiation of high and low readiness youth.

Results from the current investigation also have significant implications for clinicians and practitioners working with antisocial youth, in terms of the type, length, and intensity of placement. A comprehensive assessment of present and past behaviour is essential for identifying the onset of behaviours and the presence of mental health difficulties. Consequently, it is important to address readiness in youth with an early onset of antisocial behaviours in order to contribute to increased program engagement and performance. Assessments of readiness will help increase knowledge as to what potential treatment barriers exist within youth, help guide the decision-making process in terms of the timing and strategies employed in treatment, and provide guidance to community agencies responsible for the treatment of antisocial youth as to the specific and identifiable needs that require attention. 


\section{References}

Andrews, D.A. (2002). Principles of effective correctional programming. Compendium 2000, Correctional Service of Canada.

Andrews, D.A., \& Bonta, J. (2003). The psychology of criminal conduct, $3^{\text {rd }}$ Edition. Ohio: Anderson Publishing.

Andrews, D.A., Zinger, I., Hoge, R.D., Bonta, J., Gendreau, P., \& Cullen, F.T. (1990). Does correctional treatment work? A clinically relevant and psychologically informed meta-analysis. Criminology, 28, 369-304.

Antonowicz, D.H., \& Ross, R.R. (1994). Essential components of successful rehabilitation programs for offenders. International Journal of Offender Therapy and Comparative Criminology, 38(2), 97-104.

Battjes, R.J., Onken, L.S., \& Delany, P.J. (1999). Drug abuse treatment entry and engagement: Report of a meeting on treatment readiness. Journal of Clinical Psychology, 55(5), 643-657.

Blankenship, J., Dansereau, D.F., \& Simpson, D.D. (1999). Cognitive enhancements of readiness for corrections-based treatment for drug abuse. The Prison Journal, $79(4), 431-445$.

Breda, C., \& Heflinger, C.A. (2004). Predicting incentives to changes among adolescents with substance abuse disorder. American Journal of Drug and Alcohol Abuse, 30(2), 251-267.

Bushway, S.D., Piquero, A.R., Broidy, L.M., Cauffman, E., \& Mazzerolle, P. (2001). An empirical framework for studying desistance as a process. Criminology, 39, 491- 
515.

Carlson, B.E., \& Barr, W.B., \& Young, K.J. (1994). Factors associated with treatment outcomes of male adolescents. Residential Treatment for Children and Youth, 12 (1), 39-58.

DeLeon, G., Melnick,G., Kressell, D., \& Jainchill, N. (1994). Circumstances, motivation, readiness, and suitability: Predicting retention in therapeutic community treatment - the CMRS scales. American Journal of Drug and Alcohol Abuse, 20(4), 495-515.

Donnellan, M.B., Ge, X., \& Wenk, E. (2000). Cognitive abilities in adolescent-limited and life-course-persistent criminal offenders. Journal of Abnormal Psychology, 109(3), 396-402.

Dowden, C., \& Andrews, D.A. (1999). What works in young offender treatment: A meta-analytic review. Forum on Corrections Research, 11(2), 21-24.

Fergusson, D.M., Horwood, L.J., \& Nagin, D.S. (2000). Offending trajectories in a New Zealand birth cohort. Criminology, 38(2), 525-551.

Gorske, T.T., Srebalus, D.J., \& Walls, R.T. (2003). Adolescents in residential centers: Characteristics and treatment outcome. Children and Youth Services Review, $25(4), 317-326$.

Howells, K., \& Day, A. (2003). Readiness for anger management: Clinical and theoretical issues. Clinical Psychology Review, 23, 319-337.

Izzo, R.L., \& Ross, R.R. (1990). Meta-analysis of rehabilitation programs for juvenile delinquents. Criminal Justice and Behaviour, 17(1), 134-142.

Kann, R.T., \& Hanna, F.J. (2000). Disruptive behaviour disorders in children and 
adolescents: How do girls differ from boys? Journal of Counseling and Development, 78(3), 267-274.

Kazdin, A.E. (1993). Treatment of conduct-disorder: Progress and directions in psychotherapy research. Development and Psychopathology, 5, 277-310.

Latendresse, M. (2006). Predicting sex offender program attrition: The role of denial, motivation, and treatment readiness. Unpublished Master's thesis, Carleton University.

Leistico, A.M.R., \& Salekin, R.T. (2003). Testing the reliability and validity of the Risk, Sophistication-Maturity and Treatment Amenability Instrument (RST-i): An assessment tool for juvenile offenders. International Journal of Forensic Mental Health, 2(2), 101-117.

Loeber, R. (1991). Antisocial behaviour: More enduring than changeable? Journal of the American Academy of Child and Adolescent Psychiatry, 30, 393-397.

Loeber, R. (1990). Development and risk factors of juvenile antisocial behaviour and delinquency. Clinical Psychology Review, 10, 1-41.

Loeber, R. \& Hay, D.F. (1997). Key issues in the development of aggression and violence from childhood to early adulthood. Annual Review of Psychology, 48, $371-410$.

Loeber, R. \& Hay, D.F. (1994). Developmental approaches to aggression and conduct problems. In M. Rutter \& D.F. Hay (Eds.), Development through life: A handbook for clinicians (pp. 488-516). Oxford, England: Blackwell Scientific.

Loeber, R., Keenan, K., \& Zhang, Q. (1997). Boys' experimentation and persistence in developmental pathways toward a serious delinquency. Journal of Child and 
Family Studies, 6(3), 321-357.

Loeber, R., \& Schmaling, K. (1985). Empirical evidence for overt and covert patterns of antisocial conduct problems. Journal of Abnormal Child Psychology, 13, 337-352.

Loeber, R, Stouthamer-Loeber, M., \& Green, S.M. (1991). Age at onset of problem behaviour in boys, and later disruptive and delinquent behaviours. Criminal Behaviour and Mental Health, 1(3), 229-246.

Marshall, W., \& Firestone, P. (1999). Abnormal psychology perspectives. Ontario: Prentice-Hall Canada.

Marshall, W., \& Molden, H. (2005). Preparatory programs for sexual offenders. In W. L. Marshall, Y. M. Fernandez, L. E. Marshall, \& G. A. Serran (Eds.). Sexual Offender Treatment: Controversial Issues. Chichester, U.K.: Wiley.

Moffitt, T.E. (2003). Life-Course-Persistent and Adolescent-Limited antisocial behaviour: A 10-year research review and a research agenda. In B.B. Lahey, T.E. Moffitt, \& A. Caspi (Eds.). Causes of conduct disorder and juvenile delinquency (pp. 49-75). New York, NY: Guilford Press.

Moffitt, T.E. (1993). Adolescent-limited and life-course-persistent antisocial behavior: A developmental taxonomy. Psychological Review, 100(4), 674-701.

Moffitt, T., Caspi, A., Dickson, N., Silva, P., \& Stanton, W. (1996). Childhood-onset versus adolescent-onset antisocial conduct problems in males: Natural history from ages 3 to 18 years. Development and Psychopathology, 8, 399-424.

Moffitt, T.E., Caspi, A., Harrington, H., \& Milne, B.J. (2002). Males on the life-coursepersistent and adolescence-limited antisocial pathways: Follow-up at age 26 years. Development and Psychopathology, 14, 179-207. 
O’Leary, T., \& Monti, P.M. (2004). Motivational enhancement and other brief interventions for adolescent substance abuse: Foundation, applications and evaluations. Addiction, 99(Suppl. 2), 63-75.

Page, G.L., \& Scalora, M.J. (2004). The utility of locus of control for assessing juvenile amenability to treatment. Aggression and Violent Behavior, 9, 523-534.

Patterson, G.R. (1986). Performance models for antisocial boys. American Psychologist, $41(4), 432-444$.

Preston, D.L., \& Murphy, S. (1997). Motivating treatment-resistant clients in therapy. Correctional Service of Canada, Correctional Research and Development, Forum on Corrections Research, 9(2). Retrieved June 13, 2006, from http://www.cscscc.gc.ca/text/pblct/forum/e092/092i_e.pdf.

Prochaska, J.O., \& DiClemente C.C. (1982). Transtheoretical therapy: Toward a more integrative model of change. Psychotherapy: Theory, Research and Practice, 20, 161-173.

Raine, A., Moffitt, T.E., Caspi, A., Loeber, R., Stouthamer-Loeber, M., \& Lynam, D. (2005). Neurocognitive impairments in boys on the life-course persistent antisocial path. Journal of Abnormal Psychology, 114(1), 38-49.

Russell, K. (2005). Preliminary results of a study examining the effects of outdoor behavioral healthcare treatment on levels of depression and substance use frequency. Journal of Experiential Education, 1, 1-21.

Sampson, R.J., \& Laub, J.H. (2003). Life-course desisters? Trajectories of crime among delinquent boys followed to age 70. Criminology, 41(3), 555-592.

Serin, R. (1998). Treatment responsivity, intervention, and reintegration: A conceptual 
model. Correctional Service of Canada, Correctional Research and Development, Forum on Corrections Research, 10(1). Retrieved September 15, 2005, from http://www.csc-scc.gc.ca/text/pblct/forum/e101/e101f_e.shtml.

Serin, R., \& Kennedy, S. (1997). Treatment readiness and responsivity: Contributing to effective correctional programming. Correctional Service of Canada, Correctional Research and Development, Research Report R-82. Retrieved September 15, 2005, from http://www.csc-scc.gc.ca/text/rsrch/reports/r54/er54.pdf

Serin, R., Kennedy, S., \& Mailloux, D.L. (2005). Manual for the Treatment Readiness, Responsivity and Gain Scale: Short Version (TRRG:SV). Carleton University, Ottawa, Ontario, Canada.

Shamsie, J., Sykes, C., \& Hamilton, H. (1994). Continuity of care for conduct disordered youth. Canadian Journal of Psychiatry, 39(7), 415-420.

Sia, T.L., Dansereau, D.F., \& Czuchry, M.L. (2000). Treatment readiness training and probationers' evaluation of substance abuse treatment in a criminal justice setting. Journal of Substance Abuse and Treatment, 19, 459-467.

Silverthorn, P., Frick, P.J., \& Reynolds, R. (2001). Timing of onset and correlates of severe conduct problems in adjudicated girls and boys. Journal of Psychopathology and Behavioral Assessment, 23(3), 171-181.

Steiner, H., \& Dunne, J. (1997). Practice parameters for the assessment and treatment of children and adolescents with conduct disorder. Journal of the American Academy of Child and Adolescent Psychiatry, 36(10S) Supplement, 122S-139S.

Stouthamer-Loeber, M., Wei, E., Loeber, R., \& Masten, A.S. (2004). Desistance from persistent serious delinquency in the transition to adulthood. Development and 
Psychopathology, 16, 897-918.

Tabachnick, B.G. \& Fidell, L.S. (2000). Using Multivariate Statistics (4 ${ }^{\text {th }}$ Edition.). Boston, MA: Ally and Bacon.

Taylor, J., Iacono, W.G., \& McGue, M. (2000). Evidence for a genetic etiology of earlyonset delinquency. Journal of Abnormal Psychology, 109(4), 634-643.

Tolan, P.H., \& Gorman-Smith, D. (1998). Development of serious and violent offending careers. In R. Loeber, \& D.P. Farrington (Eds.), Serious and violent juvenile offenders: Risk factors and successful interventions (pp. 68-85). Thousand Oaks, CA: Sage Publications.

Ward, T., Day, A., Howells, K., \& Birgden, A. (2004). The multifactor offender readiness model. Aggression and Violent Behavior, 9, 645-673.

Williamson, P., Day, A., Howells, K., Bubner, S., \& Jauncey, S. (2003). Assessing offender readiness to change problems with anger. Psychology, Crime and Law, 9(4), 295-307. 
Treatment Readiness and Antisocial Youth 74

Appendix A: Structured Client Information System 


\section{Client Onformation Oystem}

Referral date:

CASE \#:

REFERRAL \#:

OLD CASE \#:

Qhient' Oemagnaphic OFformation

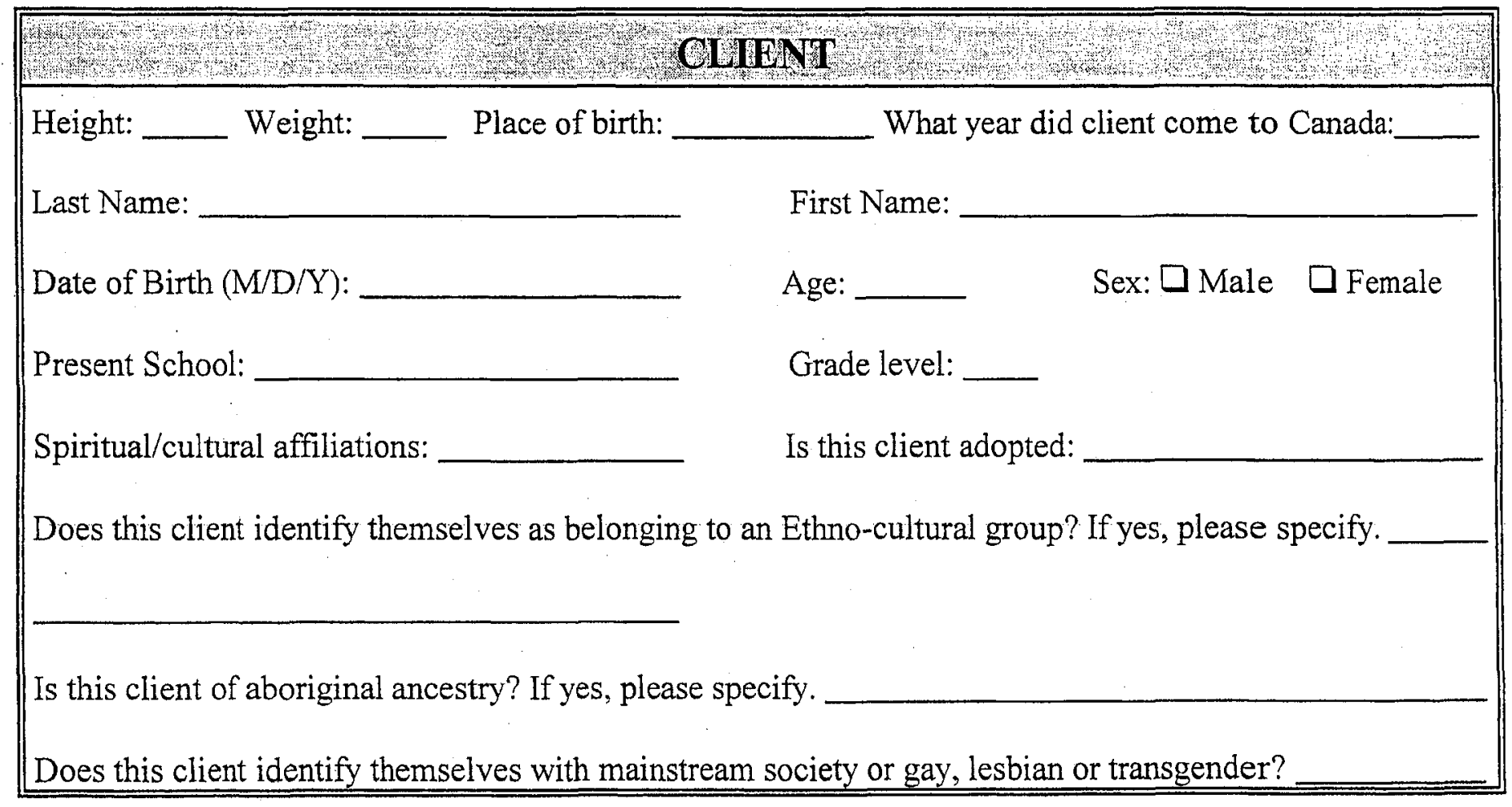




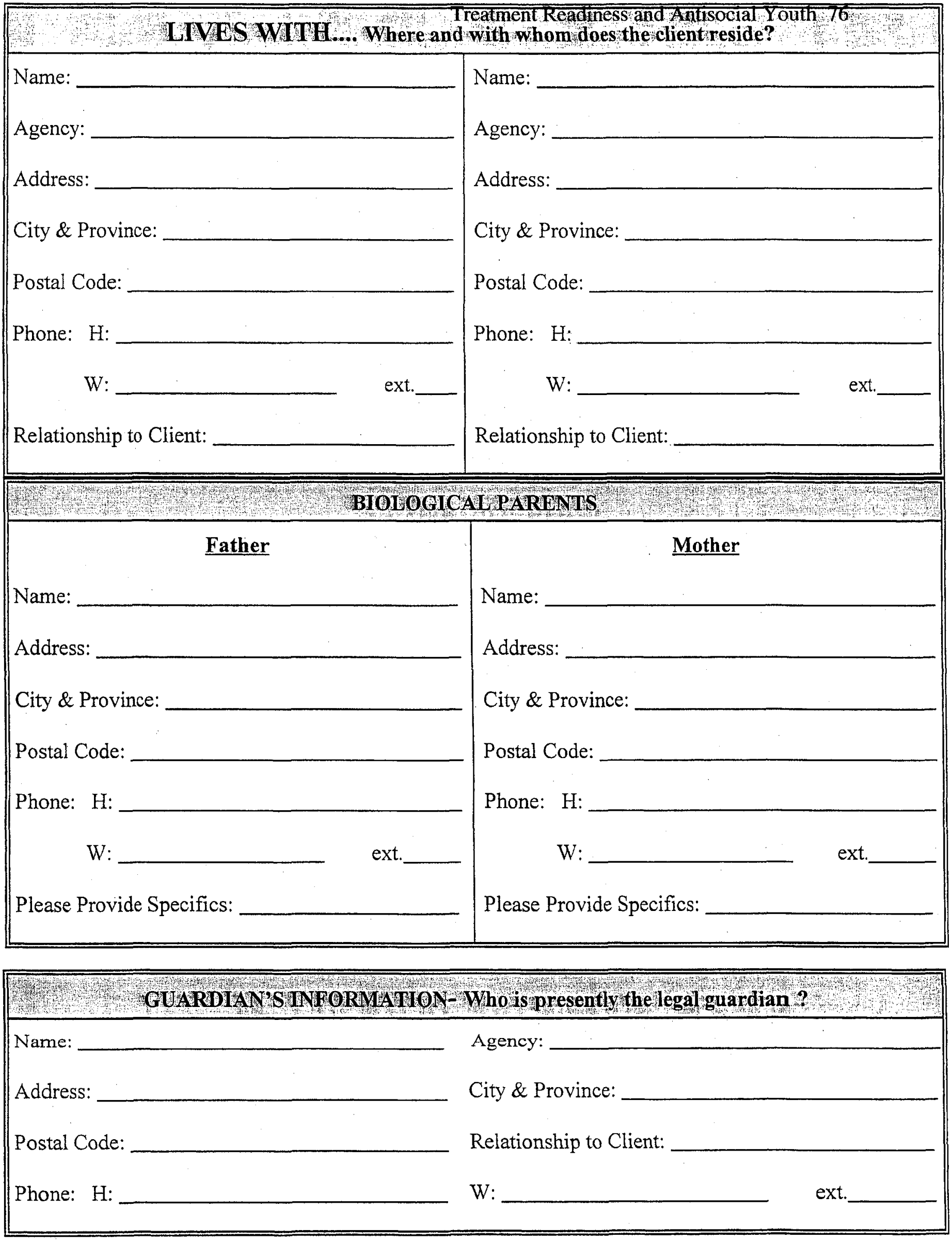


OAdditional Onformation

Treatment Readiness and Antisocial Youth 77

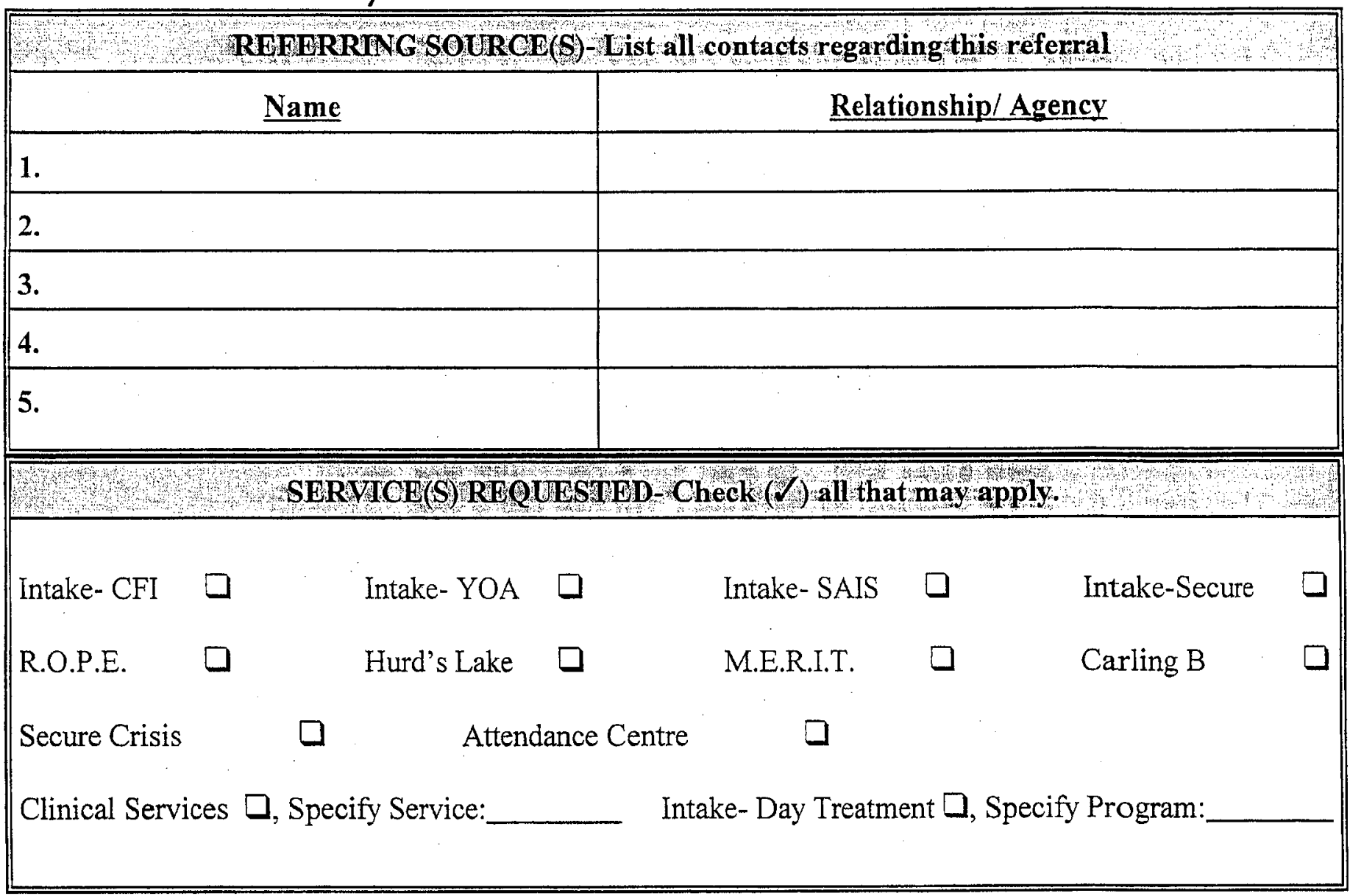




\begin{tabular}{|c|c|c|}
\hline+ & PRESENTING PR & S-Check $(\checkmark)$ all that apply. \\
\hline \multirow[t]{3}{*}{$\mathbf{Y} / \mathbf{N}$} & Definition & Please provide specifics \\
\hline & $\begin{array}{l}\text { In need of protection: } \\
\text { Solely defined by CAS, legal definition, Is the child a } \\
\text { society or crown ward? }\end{array}$ & \\
\hline & $\begin{array}{l}\text { Abuse/Trauma: } \\
\text { Sexual, Physical, Emotional }\end{array}$ & $\begin{array}{l}\text { Has your child ever been abused? If yes, please explain. } \\
\text { (SEE BCFPI) }\end{array}$ \\
\hline & $\begin{array}{l}\text { Neglect: } \\
\text { Periods left unsupervised. } \\
\text { Allowed to roam after dark. } \\
\text { Complaints from school- no lunch. } \\
\text { No breakfast before school. } \\
\text { Lack of adequate clothing. }\end{array}$ & $\begin{array}{l}\text { Have you ever had the Children's Aid Society involved } \\
\text { with your family. If yes, please explain. } \\
\text { (SEE BCFPI) }\end{array}$ \\
\hline & False Allegations & $\begin{array}{l}\text { Must have been reported to police or social service } \\
\text { agency }\end{array}$ \\
\hline & $\begin{array}{l}\text { Dangerous: } \\
\text { As defined by the referring agent }\end{array}$ & Would you consider your child dangerous? \\
\hline & $\begin{array}{l}\text { Stubborn: } \\
\text { Preschool Onset }\end{array}$ & $\begin{array}{l}\text { Would you consider your child stubborn. If yes, at what } \\
\text { age did you notice your child being stubborn? }\end{array}$ \\
\hline & $\begin{array}{l}\text { Early Onset: } \\
\text { Before Age of } 6\end{array}$ & $\begin{array}{l}\text { At what age did you notice behavioural problems with } \\
\text { your child? }\end{array}$ \\
\hline & $\begin{array}{l}\text { Frequent Anti-Social Acts } \\
\text { Please circle one that applies }\end{array}$ & $\begin{array}{ll}\text { 1- less than once a month } & \text { 4-2-4 times a week } \\
\text { 2- once a month } & 5-\text { once or twice a } \\
\text { day } & \\
\begin{array}{l}\text { 3- } 2-3 \text { times in a } 2 \text { week period } \\
\text { day }\end{array} & 6-3 \text { or more times a }\end{array}$ \\
\hline & Variety of Anti-Social Acts & $\begin{array}{l}\text { What typical behaviours does your child exhibit? Please } \\
\text { list types of behaviour. }\end{array}$ \\
\hline & $\begin{array}{l}\text { Variety of Settings } \\
\text { Please circle all that apply }\end{array}$ & Community \\
\hline
\end{tabular}




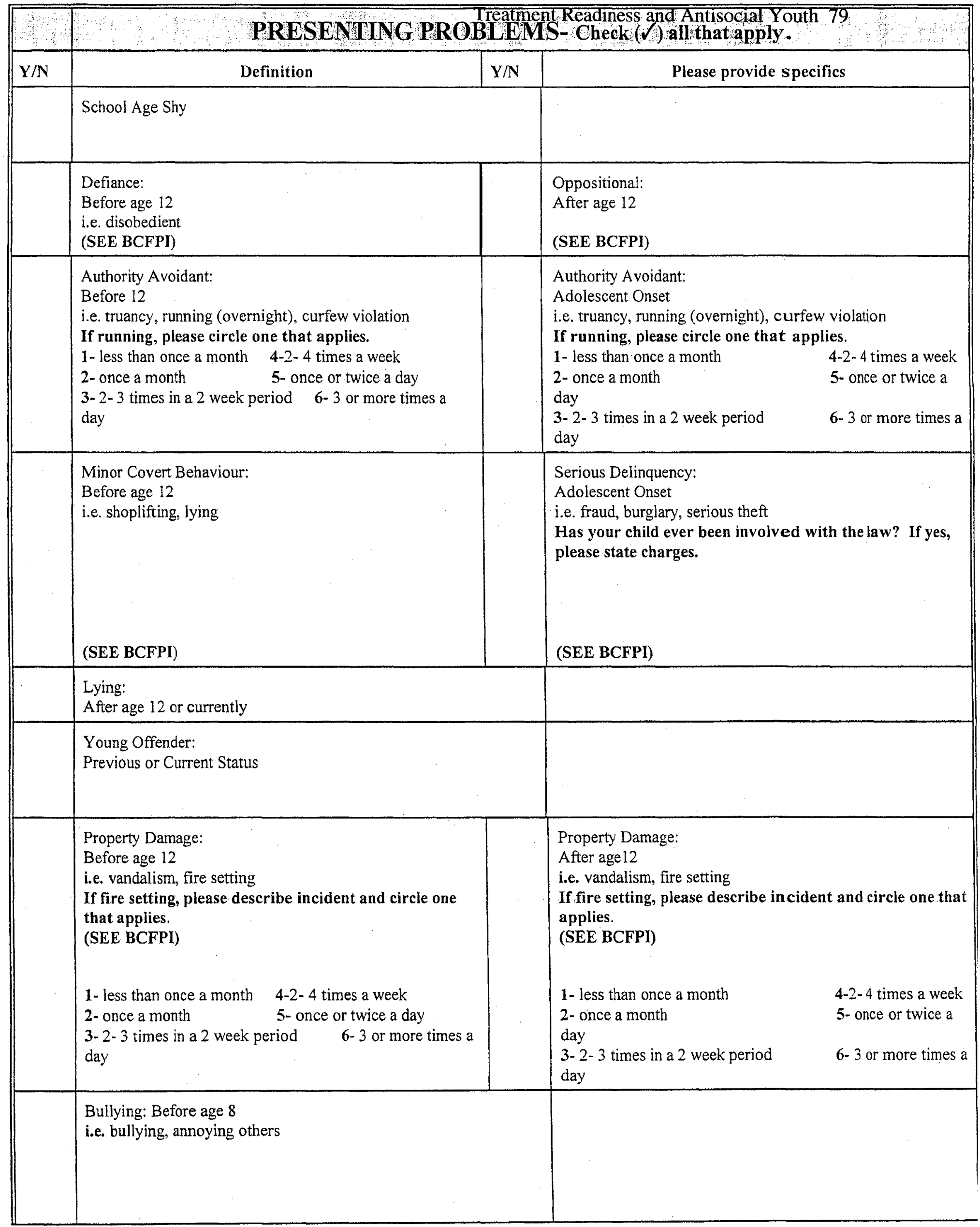




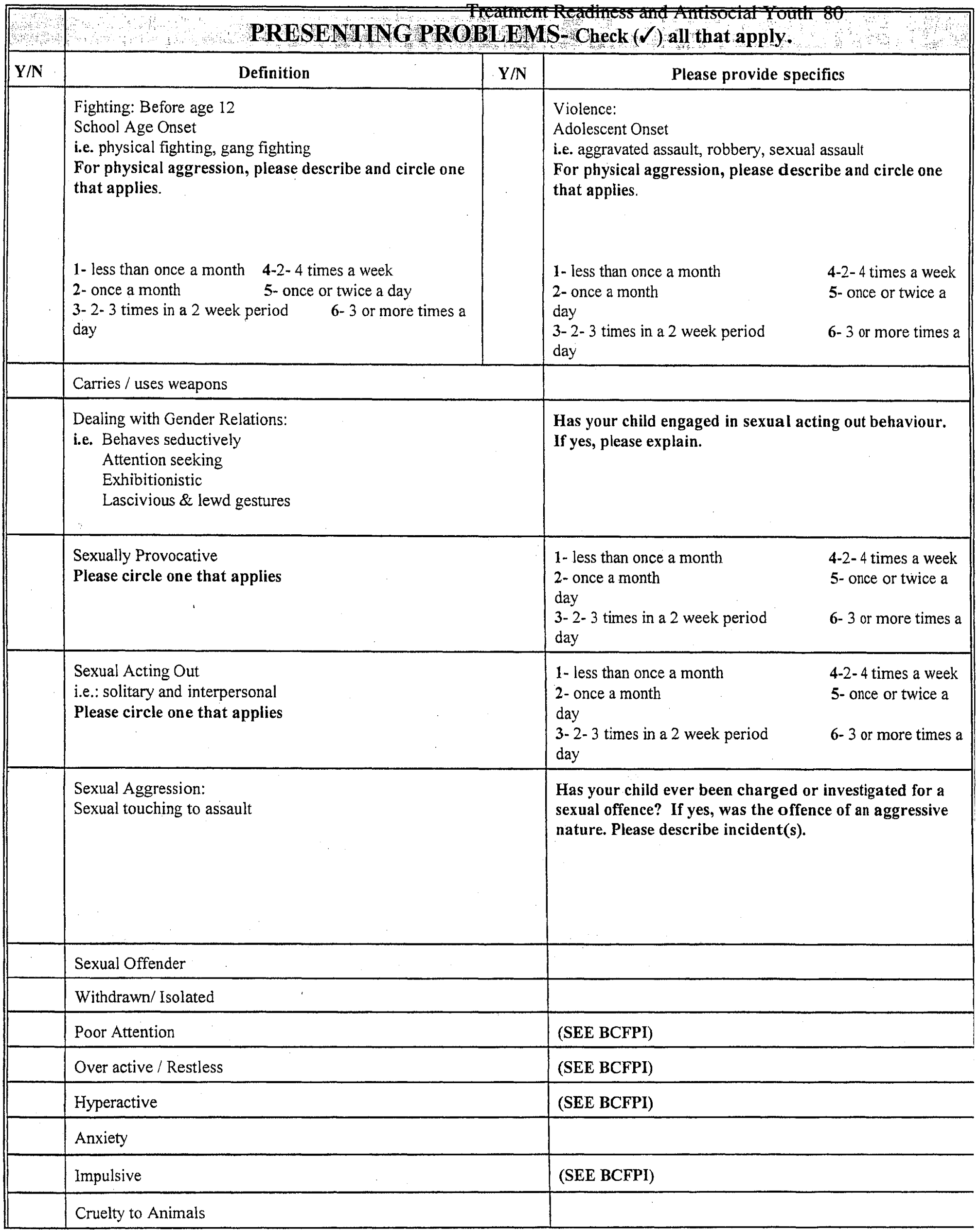




\begin{tabular}{|c|c|c|c|}
\hline \multirow{3}{*}{$\mathbf{Y} / \mathbf{N}$} & \multicolumn{3}{|c|}{ PRESENTING PROBLEMS-Check $(\checkmark)$ all that apply. } \\
\hline & Definition & \multicolumn{2}{|c|}{ Please provide specifics } \\
\hline & $\begin{array}{l}\text { Chemical Dependency } \\
\text { Self-admitted or diagnosed } \\
\text { Please circle one that applies }\end{array}$ & $\begin{array}{l}\text { 1- less than once a month } \\
2 \text { - once a month } \\
\text { day } \\
3-2-3 \text { times in a } 2 \text { week period } \\
\text { day }\end{array}$ & $\begin{array}{l}\text { 4-2- } 4 \text { times a week } \\
\text { 5- once or twice a } \\
\text { 6- } 3 \text { or more times a }\end{array}$ \\
\hline & Suicidal Ideations & & \\
\hline & $\begin{array}{l}\text { Self-Injury / Self-Mutilation } \\
\text { Please provide specifics and circle one that applies }\end{array}$ & $\begin{array}{l}\text { 1- less than once a month } \\
2 \text { - once a month } \\
\text { day } \\
3-2-3 \text { times in a } 2 \text { week period } \\
\text { day }\end{array}$ & $\begin{array}{l}\text { 4-2- } 4 \text { times a week } \\
\text { 5- once or twice a } \\
\text { 6- } 3 \text { or more times a }\end{array}$ \\
\hline & $\begin{array}{l}\text { Suicidal Attempts } \\
\text { Please circle one that applies }\end{array}$ & $\begin{array}{l}\text { 1- less than once a month } \\
2 \text { - once a month } \\
\text { day } \\
\text { 3- } 2 \text { - } 3 \text { times in a } 2 \text { week period } \\
\text { day }\end{array}$ & $\begin{array}{l}\text { 4-2- } 4 \text { times a week } \\
\text { 5- once or twice a } \\
\text { 6- } 3 \text { or more times a }\end{array}$ \\
\hline & $\begin{array}{l}\text { Suicidal Gesturing } \\
\text { Please circle one that applies }\end{array}$ & $\begin{array}{l}\text { 1- less than once a month } \\
2 \text { - once a month } \\
\text { day } \\
\text { 3- } 2-3 \text { times in a } 2 \text { week period } \\
\text { day }\end{array}$ & $\begin{array}{l}\text { 4-2- } 4 \text { times a week } \\
\text { 5- once or twice a } \\
\text { 6- } 3 \text { or more times a }\end{array}$ \\
\hline & Externalizing Behaviour/ Generic & & \\
\hline & $\begin{array}{l}\text { Intimidation: } \\
\text { Adolescent Onset } \\
\text { i.e. threats of harm, verbal aggression } \\
\text { (SEE BCFPI) }\end{array}$ & $\begin{array}{l}\text { For verbal aggression, please } \\
1 \text { - less than once a month } \\
2 \text { - once a month } \\
\text { day } \\
3-2-3 \text { times in a } 2 \text { week period } \\
\text { day }\end{array}$ & $\begin{array}{l}\text { ne that applies } \\
\text { 4-2- } 4 \text { times a week } \\
\text { 5- once or twice a } \\
\text { 6- } 3 \text { or more times a }\end{array}$ \\
\hline & $\begin{array}{l}\text { Verbal aggression- applies to females only: } \\
\text { i.e. gossiping, insults. }\end{array}$ & & \\
\hline & Domestic Violence & $\begin{array}{l}\text { Has your child ever been a wit } \\
\text { home? }\end{array}$ & violence in the \\
\hline & Single Parent & & \\
\hline & $\begin{array}{l}\text { Low Income: } \\
\text { Below poverty level with job or welfare }\end{array}$ & $\begin{array}{l}\text { Describe your total family ine } \\
\text { (SEE BCFPI) }\end{array}$ & er the past year. \\
\hline & $\begin{array}{l}\text { Special Educational Needs: } \\
\text { LD, Learning Problems }\end{array}$ & Client must be more than 2 y & hind in school. \\
\hline
\end{tabular}




\begin{tabular}{|c|c|c|c|}
\hline PR & 7 & NI & $\begin{array}{l}\text { Treatment Readiness and Antisocial Youth } 82 \\
\text { ING PROBLEMS - Check }(\checkmark) \text { all that apply. }\end{array}$ \\
\hline Professional diagnosis & $Y$ & $\mathbf{N}$ & By whom and date of diagnosis \\
\hline Adjustment disorder & & & \\
\hline Affective Disorder & & & \\
\hline Anxiety disorder & & & \\
\hline Attachment Disorder & & & \\
\hline Attention Deficit Disorder & & & \\
\hline $\begin{array}{l}\text { Attention Deficit Hyperactivity } \\
\text { Disorder }\end{array}$ & & & \\
\hline Borderline IQ & & & \\
\hline $\begin{array}{l}\text { Character Disorder: } \\
\text { Diagnosis of being character } \\
\text { damaged (i.e.: personality } \\
\text { disorder) }\end{array}$ & & & \\
\hline Conduct disorder & & & \\
\hline Convulsive disorder & & & \\
\hline Depression & & & (SEE BCFPI) \\
\hline Dysthymia & & & \\
\hline Developmental Delay & & & \\
\hline MBD - brain injury & & & \\
\hline Mentally Deficient & & & \\
\hline Motor control delay & & & \\
\hline Obsessive-compulsive disorder & & & \\
\hline Oppositional Defiant Disorder & & & \\
\hline Other diagnosis & & & \\
\hline Perceptual motor delay & & & \\
\hline $\begin{array}{l}\text { Post Traumatic Stress Disorder } \\
\text { Including flashbacks }\end{array}$ & & & $\begin{array}{l}\text { If flashbacks, please circle one that applies. } \\
\begin{array}{ll}\text { 1- less than once a month } & \text { 4-2- } 4 \text { times a week } \\
\text { 2- once a month } & 5-\text { once or twice a day } \\
\text { 3-2-3 times in a } 2 \text { week period } & \text { 6- } 3 \text { or more times a day } \\
\end{array}\end{array}$ \\
\hline Speech / language delay & & & \\
\hline Superior intellect & & & \\
\hline
\end{tabular}




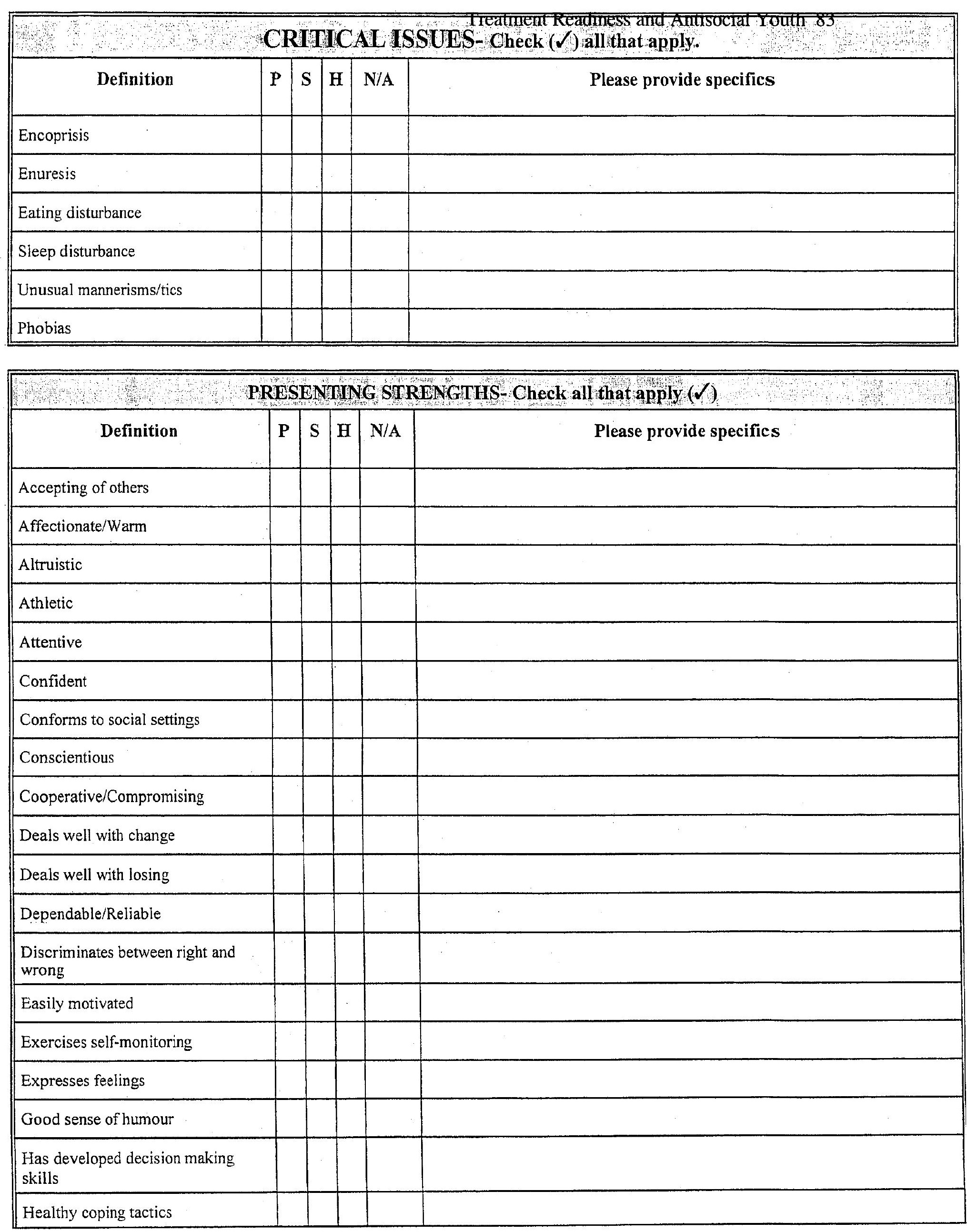




\section{PRESENTING STRENGTHS- Check all that apply $(\mathscr{V})$}

\begin{tabular}{|c|c|c|c|c|c|}
\hline Definition & $\mathbf{P}$ & $\mathbf{S}$ & $\mathbf{H}$ & N/A & Please provide specifics \\
\hline \multicolumn{6}{|l|}{ High achiever } \\
\hline \multicolumn{6}{|l|}{ Imaginative } \\
\hline \multicolumn{6}{|l|}{ Independent } \\
\hline \multicolumn{6}{|l|}{ Leadership qualities } \\
\hline \multicolumn{6}{|l|}{ Listens well } \\
\hline \multicolumn{6}{|l|}{ Open to experience } \\
\hline \multicolumn{6}{|l|}{ Optimistic } \\
\hline \multicolumn{6}{|l|}{ Outgoing/personable/sociable } \\
\hline \multicolumn{6}{|l|}{ Polite } \\
\hline \multicolumn{6}{|l|}{ Positive Self-Image } \\
\hline \multicolumn{6}{|l|}{$\begin{array}{l}\text { Respect other personal property/ } \\
\text { space }\end{array}$} \\
\hline \multicolumn{6}{|l|}{ Self-control } \\
\hline \multicolumn{6}{|l|}{ Strong academically } \\
\hline \multicolumn{6}{|l|}{ Strong Friendships (healthy) } \\
\hline \multicolumn{6}{|l|}{ Sympathetic/Empathetic } \\
\hline \multicolumn{6}{|l|}{ Trust worthy/Honest } \\
\hline \multicolumn{6}{|l|}{ Trusting } \\
\hline Welcomes feedback from others & & & & & \\
\hline
\end{tabular}

\section{OTHER}

\section{Current Living Situation}

Health Card \#

Currently on Medication:

Please Provide Specifics:

$\square$ Yes $\square$ No

Allergies:

Please Provide Specifics:

$\square$ Yes $\quad \square$ No

Geographical Area

Family Composition 
Treatment Readiness and Antisocial Youth 85

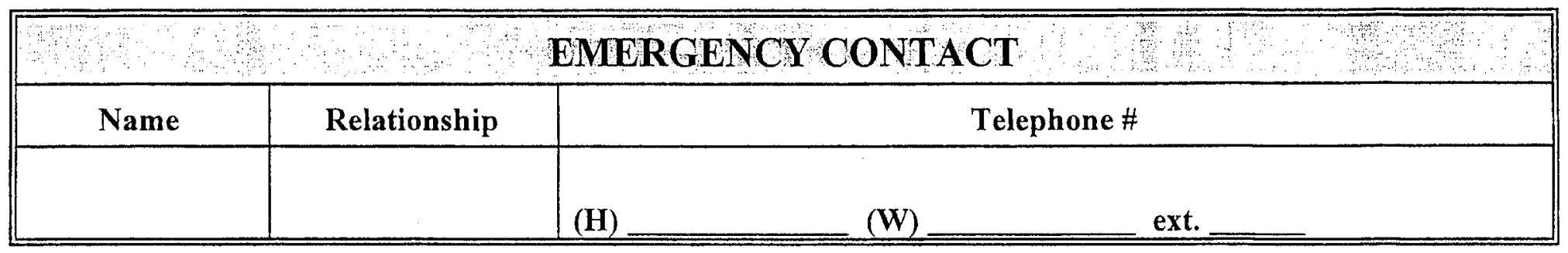

\section{OTHER AGENCY INYOLVEMENT}

\section{Agency:}

From:

To:

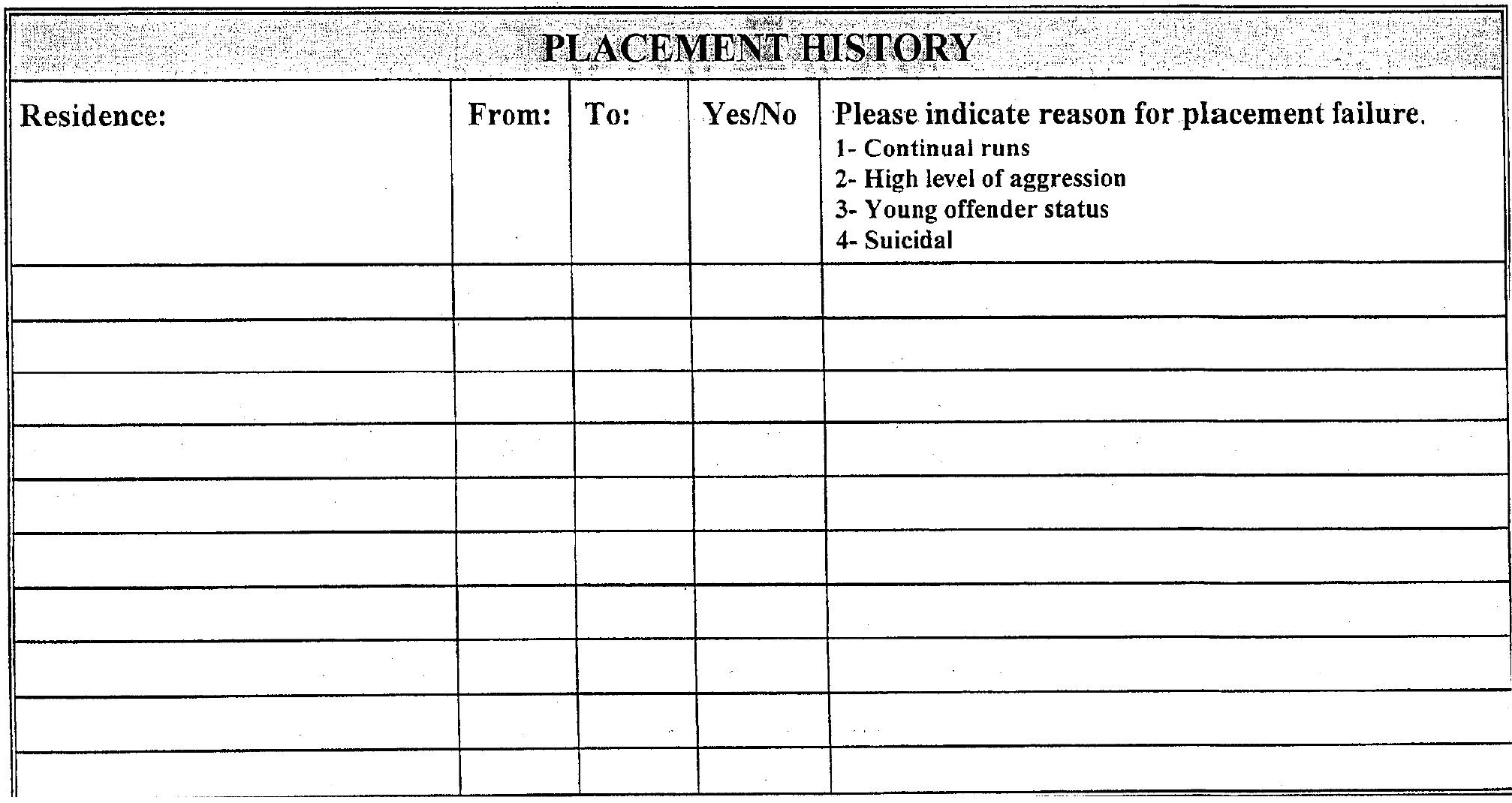


Treatment Readiness and Antisocial Youth 86

SIGNIFICANTOTHERS- specify Brothers, Sisters, Lawyers, Doctors, Probation Officer, etc.

Name:

Address:

City \& Province:

Postal Code:

Phone: H:

W:

ext.

Relationship to Client:

Please Provide Specifics:

Name:

Address:

City \& Province:

Postal Code:

Phone: $\mathrm{H}$ :

W:

ext.

Relationship to Client:

Please Provide Specifics:

Name:

Name:

Address:

City \& Province:

Postal Code:

Phone: $\mathrm{H}$ :

W:

ext.

Address:

City \& Province:

Postal Code:

Phone: $\mathrm{H}$

W:

ext

Relationship to Client:

Please Provide Specifics:

Relationship to Client:

Please Provide Specifics:

Name:

Address:

City \& Province:

Postal Code:

Name:

Address:

City \& Province:

Postal Code:

Phone: $\mathrm{H}$

W:

ext.

Relationship to Client:

Please Provide Specifics:

Phone: $\mathrm{H}$ :

W:

ext.

Relationship to Client:

Please Provide Specifics:

\section{Staff Signature:}

Date: 
Treatment Readiness and Antisocial Youth 87

Appendix B: Manual for the Treatment Readiness: Short Version 


\section{Manual for the Treatment Readiness: Short Version} (TR:SV)

Ralph C. Serin, Sharon Kennedy, and Donna L. Mailloux

October 2005

Carleton University,

Ottawa, Ontario, Canada 


\section{INTRODUCTION}

Treatability is a multi-faceted concept that we consider encompassing an individual's readiness for and responsivity to treatment intervention. It is suggested that the assessment of treatability be an integral component of correctional planning to facilitate the appropriate placement of offenders into correctional programs.

The purpose of this scale is to assist staff to systematically assess an offender's readiness and responsivity to treatment and to subsequently measure the degree to which gains have been made. These items have been selected based on a review of the relevant literature and discussions with clinicians and program staff.

The items that comprise the TRRG:SV were selected based on a factor analysis with the original scale of 50 items in a sample of 265 male offenders entering a cognitive skills program. Principle components analysis revealed one underlying factor for both the treatment readiness and responsivity domain. A reduction in items from 22 to 8 reduced the overall consistency for both domains from .90 to .82 , still within the range for excellent internal consistency. 
Each item has a specific behavioral anchor and description to assist in scoring. Questions for each item are provided simply as a guide for those staff wishing the format of a semi-structured interview. We recommend the questions simply be incorporated into existing interview-based assessment strategies.

Individual items are summed in order to provide a total score that represents an individual's readiness and responsivity for treatment. A higher score on this scale reflects greater readiness or responsivity for treatment while a lower score reflects less readiness or responsivity for treatment.

The construct of treatment readiness and responsivity are not conceptualized as trait specific but rather as a process that reflects a continuum of change. For this reason it is recommended that the ratings be completed prior to treatment and at the conclusion of the treatment program. These ratings, to be completed by program staff, may then be used as a measure of change. Although it is impossible to predetermine how much contact is required before you can complete the pre-treatment assessment, it may be that up to 3 sessions will be necessary.

Treatment readiness and responsivity are critical in the process of determining treatment needs and placement. For instance, offenders who score low on readiness and responsivity may benefit from a treatment 
primer session in order to prepare them for a treatment program, maximizing the potential treatment gains.

\section{$\underline{\text { Treatment Readiness }}$}

Treatment readiness is a domain that captures an individual's willingness to engage in the treatment process. For some, they see themselves as having very few problems that require therapeutic intervention and do not have any desire to make changes. These individuals tend to be forced into treatment and are reluctant to put forth any effort into changing. Others may be aware of the problems in their lives but are hesitant to make a commitment to change. On the other extreme are those who are committed to changing and are enthusiastic about modifying their behaviors.

The treatment readiness domain is intended to operationalize this continuum in an effort to assist clinicians in determining treatment placement. This domain has excellent internal consistency producing an alpha of .83 in a sample of 265 male offenders entering a cognitive skills program. The items produced factor loadings in the very good to excellent range (.60 to .77$)$ with a mean of .67 .

Norms 
Incarcerated men offender. Among incarcerated men offenders in cognitive skills program ( $n=58$ to 268 ) the following scores were obtained:

\begin{tabular}{|c|c|c|c|c|}
\hline \multicolumn{5}{|l|}{ Domain } \\
\hline \multicolumn{5}{|l|}{ 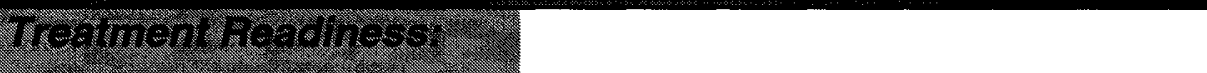 } \\
\hline 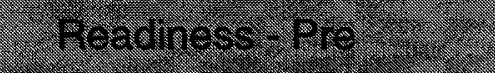 & 268 & 12.54 & 5.03 & 1 to 24 \\
\hline 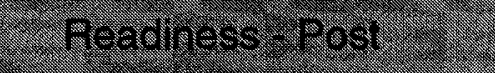 & 207 & 16.61 & 4.95 & 3 to 24 \\
\hline 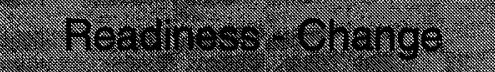 & 207 & 3.59 & 3.58 & -11 to 14.5 \\
\hline \multicolumn{5}{|l|}{ Trestmont responsivity } \\
\hline 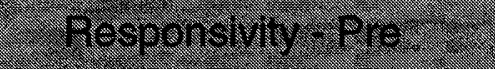 & 268 & 13.68 & 4.61 & 2 to 24 \\
\hline jespons. & 207 & 17.21 & 4.29 & 2 to 24 \\
\hline 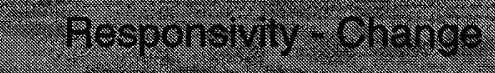 & 207 & 3.05 & 3.73 & -12 to 14.5 \\
\hline \multicolumn{5}{|l|}{ Treatom conth } \\
\hline 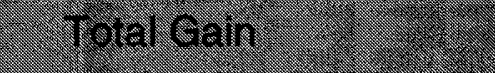 & 58 & 15.15 & 4.84 & 7 to 24 \\
\hline
\end{tabular}

Incarcerated women offenders. Among incarcerated women offenders in a cognitive skills program $(n=29)$ the following scores were obtained:

\begin{tabular}{|c|c|c|c|c|}
\hline Domain & & & & \\
\hline Thelment & & & & \\
\hline 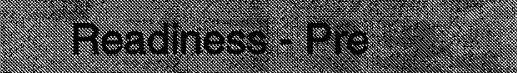 & 29 & 16.90 & 4.01 & 6.5 to 22.5 \\
\hline Readingss - Post & 29 & 21.86 & 2.57 & 14 to 24 \\
\hline 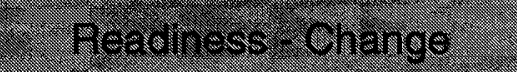 & 29 & 4.97 & 2.94 & 1 to 11 \\
\hline tra & & & & \\
\hline fesponsivily -Pre & 29 & 17.12 & 3.03 & 11 to 23 \\
\hline 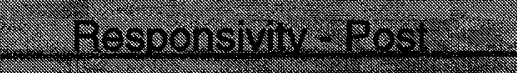 & 29 & 21.72 & 2.18 & 16 to 24 \\
\hline 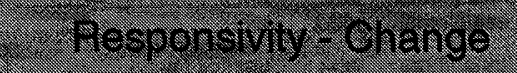 & 29 & 4.60 & 2.30 & 1 to 11.5 \\
\hline z & & & & \\
\hline Total oring & 29 & 18.84 & 3.63 & 10 to 24 \\
\hline
\end{tabular}


Incarcerated sex offenders. Among incarcerated sex offenders prior to participating in sex offender treatment $(n=39)$, the following pre-treatment scores were obtained:

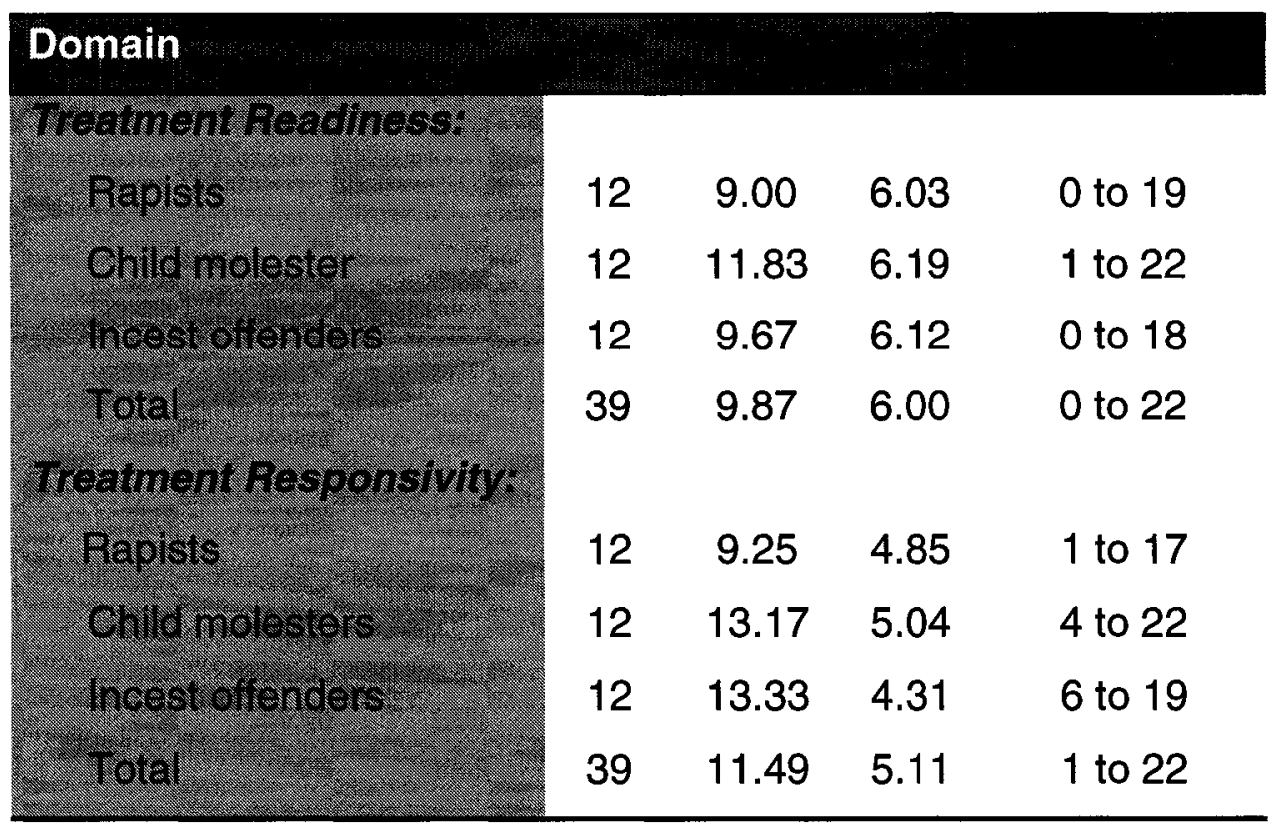




\section{TREATMENT READINESS: SHORT SCALE}

\section{Problem Recognition}

This item assesses the offender's appraisal of their current situation. This is assessed in terms of their understanding and ownership of their problems. Those who accept full responsibility without rationalization would score a "3". Those who deny responsibility would score a " 0 ".

Possible Questions:

- Did you hear a victim impact statement read in court? If so, how did that make you feel?

a How do you feel about yourself? Would you say you are satisfied or unsatisfied with who you are?

\begin{tabular}{l}
0 Views the problem is solely the result of others or \\
circumstances (no ownership). \\
$\begin{array}{l}1 . \text { Views the problem as mainly the result of others or } \\
\text { circumstances (marginal ownership). }\end{array}$ \\
\hline 2 Views self as a part of the problem (some ownership). \\
\hline 3 Views self as the major part of the problem (ownership).
\end{tabular}

\section{Benefits of Treatment}

This item is intended to tap into an offender's views regarding the overall benefits of participating in treatment. An offender who describes the long term benefits (e.g., lifestyle stability such as employment, relationships, no crime) and short term benefits (e.g., earlier release, fewer release conditions) of treatment would score a " 3 ". Those who are unable to generate any benefits would score a " 0 ".

\section{Possible Questions:}

․ What do you think will happen if you do not participate in treatment? [or if you drop out]

- If you finish this treatment program, what types of benefits might you gain? 


\begin{tabular}{|l|}
\hline 0 Sees no benefits of treatment. \\
\hline 1 Able to identify at least one long term and short term benefit of \\
treatment.
\end{tabular}

\section{Treatment Interest}

This item addresses an offender's views about treatment. Those who describe treatment as beneficial to themselves and to others (e.g., family, friends, community) would score a " 3 ". Those who cannot identify any benefits would score a "0".

\section{Possible Questions:}

- Why do you think someone would participate in a treatment program?

- What are your views about treatment in general? Do you think people benefit from it and how?

\begin{tabular}{|ll|}
\hline 0 & Not able to perceive benefits of treatment: \\
\hline 1 & Perceives treatment as only beneficial for self. \\
\hline 2 & Perceives treatment as beneficial for self or others. \\
\hline 3 & Perceives treatment as beneficial for self and others. \\
\hline
\end{tabular}

\section{Treatment Distress}

This item is intended to address an offender's state of emotional distress regarding treatment. Offenders whose commitment to treatment is accompanied or prompted by emotional distress (notably anxiety or depression) warrant a score of "3", but only if they recognize the distress. Those who appear emotionally unconcerned and indifferent about the need for change score "0".

\section{Possible Questions:}

- How does the idea of participating in treatment make you feel? [If you are in treatment how did you feel before beginning treatment]

- What motivated you to consider participation in a treatment program? [looking for distress cues not cost/benefits] 
0 Indifferent (absence of emotional distress) and sees no need for treatment.

1 Distressed, but does not motivate to consider change.

2 Distress motivates them to consider changing.

3 Evidence of emotional distress and wants to participate treatment.

\section{Treatment Goals}

Goal setting assesses the ability to identify and realistically create treatment goals. This item considers the knowledge and skills necessary for treatment gain. For example, someone with a lifelong history of substance abuse would score a " 0 " if their goal was abstinence without lapses following a 4 month program and a " 3 " if they are realistic about the new skills and knowledge necessary for treatment gain.

\section{Possible Questions:}

- If you were to participate in a treatment program what would you say were the issues you would need to address? How would you go about addressing these issues?

a How would you describe the treatment process? [try to get at whether they think that showing up for group will suffice or that more work is required than that]

0 Unable to set realistic treatment goals.

1 Unaware of skills and knowledge required for treatment gain.

2 Somewhat able to set realistic treatment goals.

3 Able to set realistic treatment goals.

\section{Treatment Behaviors}

This item assesses the offender's motivation for treatment. Behavioral indication of good motivation should reflect, where applicable, timely attendance at interviews and/or groups; homework completion; compliance with prior treatment; and/or positive comments about treatment as a process not an outcome. More than one of these must apply to warrant a score of " 3 ". 


\section{Possible Questions:}

- Have you participated in treatment before? If so, what is different this time?

- How did you find out about treatment? [i.e., what steps did he/she take in order to pursue treatment?]

0 Consistent behavioral indication of poor motivation.

1 Inconsistent indication of good motivation.

2 Somewhat inconsistent indication of good motivation.

3 Consistent behavioral indication of good motivation.

\section{Motivational Consistency}

This item highlights the importance of an offender's verbal statements and their actions regarding treatment. If an offender has not previously participated in treatment then this item refers to behavioral consistency outside of treatment (e.g., meets caseworker, etc...). Offenders who state they are motivated towards treatment, but show incongruence by poor attendance (late or infrequent), failure to complete homework, and/or state low motivation to other staff or offenders, warrant a score of " 0 ". Those who consistently follow through would score a " 3 ".

\section{Possible Questions:}

- [If you have participated in treatment before] How would the counselor or other group members describe you with respect to your participation? Did you go to all the sessions?

a [lf you have not participated in treatment] How would your caseworker describe you? Have you attended all planned meetings with him/her?

0 Verbal and behavioral expressions of motivation are inconsistent.

1 Often inconsistent between stated motivation and actions.

2 Somewhat inconsistent between stated motivation and actions.

3 Complete congruence between verbal and nonverbal expressions of good motivation.

\section{Treatment Support}

This item assesses the degree of support for change by others significant to the offender. Allow the offender to determine who is important to them (preferably family, friends, employer, or clergy) and then probe for degree of support from 
them. Those having no support would score a "0". Those reporting strong support would score "3".

\section{Possible Questions:}

- Who would you say is the most significant person (s) in your life?

- What kind of support do you want from this person (s)? Would you say they are providing this support for you? How do they demonstrate this support?

a Does this person (s) believe you can change?

0 Reports no external support for changing.

1. Reports minimal external support for changing.

2 Reports moderate external support for changing.

3 Reports strong external support for changing. 


\section{Treatment Readiness Score Sheet}

\section{Pre}

1. Problem Recognition

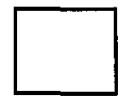

2. Benefits of Treatment

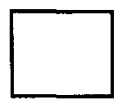

3. Treatment Interest

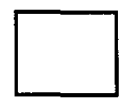

4. Treatment Distress

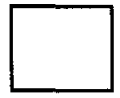

5. Treatment Goals

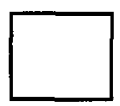

6. Treatment Behaviors

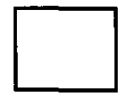

7. Motivational Consistency

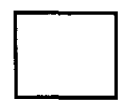

8. Treatment Support

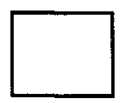

TOTAL

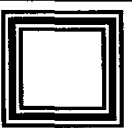


Treatment Readiness and Antisocial Youth 100

Appendix C: Crisis Interview Form 


\title{
Crisis Interview Form
}

\author{
Name of Client: \\ Date of Birth: \\ Today's Date: \\ Date of Admission:
}

1. Please tell us why you think you are here:

2. Please describe an average day in your life: 
3. A) What do you think your parents or guardian would list as your positives?

B) What would they say your negative may be?

4. What do you think needs to be worked on or changed at home (or the place you live)?

5. Have you ever received any counselling? 
6. Would you like to speak to anyone with any concerns you may have?

7. How do you think the staff at Crisis can help you and/or your family?

8. A) Would you consider your friends to be an important part of your life?

B) How have they been able to help you through the difficult time? 
9. Tell me the positive things about yourself and the things that you would like to change: 
Treatment Readiness and Antisocial Youth 105

Appendix D: Coding Manual

Reproduced with permission of the copyright owner. Further reproduction prohibited without permission. 


\section{Treatment Readiness Coding Manual}

\section{DEMOGRAPHICS}

1) Age at admission? (In years)

AGE

2) Gender:

$0 \quad$ Male

$1 \quad$ Female

3) Legal Guardianship

LEG

$0 \quad$ Lives with biological parents

1 Lives with other family member

2 Lives with foster parents

3 Lives in group home (other than RSC)

4) Criminal history: Young Offender designation?

$\begin{array}{ll}0 & \text { No } \\ 1 & \text { Yes }\end{array}$

\section{MENTAL HEALTH DIAGNOSES}

5) Is there a diagnosis of a mental health disorder?

DIAG
$0 \quad$ No
1 Yes (describe)

6) Is there comorbidity of mental health disorders?

COMOR

$$
\begin{array}{ll}
0 & \text { No } \\
1 & \text { Yes }
\end{array}
$$

\# of mental health disorders:

7) Comorbid mental health diagnoses (select all that apply):
$0 \quad$ No comorbidity
1 CD with ODD
2 CD with ADHD 
3 ODD and ADHD

$4 \quad$ CD with Borderline IQ

5 ODD with Externalizing/Internalizing Disorder

6 Other

8) Does the youth have any substance abuse problems?

SUBST

$\begin{array}{ll}0 & \text { No } \\ 1 & \text { Yes }\end{array}$

\section{ANTISOCIAL BEHAVIOURS}

9) Stubborn (preschool onset)

STUBBO

$0 \quad$ No

$1 \quad$ Yes

10) Onset of antisocial behaviours

ONSET

$0 \quad$ After age 6

1 Before age 6

11) Are past antisocial behaviours frequent?

FREQ

$$
\begin{array}{ll}
0 & \text { No } \\
1 & \text { Yes }
\end{array}
$$

12) Frequency of past antisocial behaviours:

LISTFREQ

$0 \quad$ Less than once a month

1 Once a month

2 2-3 times in a two-week period

3 2-4 times a week

$4 \quad$ Once or twice a day

53 or more times a day

13) Variety of past antisocial behaviours:

VARIETY

$\begin{array}{ll}0 & \text { No } \\ 1 & \text { Yes }\end{array}$




\section{NON-AGGRESSIVE BEHAVIOURS}

14) Presence of defiance before age 12 (e.g., disobedient)

\section{DEFIANT}

$0 \quad$ No

1 Yes

15) Oppositional after age 12

OPPOS

$0 \quad$ No

16) Authority avoidant - before age 12 (e.g., truancy, running curfew violation)

AA12

$0 \quad$ No

1 Yes

17) Authority avoidant - adolescent onset (e.g., truancy, running, curfew violation) AAAO

$\begin{array}{ll}0 & \text { No } \\ 1 & \text { Yes }\end{array}$

18) Minor covert behaviours (before age 12) (e.g., shoplifting, lying)

MINCOV

$0 \quad$ No

$1 \quad$ Yes

19) Property damage (before age 12) (e.g., vandalism, fire setting, etc.)

PPB12

$0 \quad$ No

1 Yes

20) Property damage (after age 12) (e.g., vandalism, fire setting, etc.)

PPA12

$0 \quad$ No

21) Serious delinquency (adolescent onset): (e.g., fraud, burglary, serious theft)

SDAO

$\begin{array}{ll}0 & \text { No } \\ 1 & \text { Yes }\end{array}$


22) Is there evidence of antisocial behaviours being displayed in MULTIPLE settings? (Settings include home, school, community)

SETT

$0 \quad$ No

1 Yes

23) How many risk markers in total (is there presence of an early onset, and frequency and severity and multiple settings)?

ALLRISK

$0 \quad$ One risk marker is present

1 Two risk markers are present

2 Three risk markers are present

3 All four risk markers are present

\section{AGGRESSIVE BEHAVIOURS}

24) Is the youth following an aggressive or non-aggressive pathway?

AGGRESS

Note: the aggressive pathway also includes the presence of non-aggressive behaviours combined with aggressive behaviours

$0 \quad$ Non-aggressive pathway

1 Aggressive pathway

25) Onset of aggression:

AGGRESSONSET

$0 \quad$ Non-aggressive pathway

1 Aggressive pathway (early onset)

2 Aggressive pathway (adolescent onset)

26) Bullying (before age 8)

BULLY

$0 \quad$ No

$1 \quad$ Yes

27) Fighting (before age 12): includes physical fighting and aggression, gang fighting

FIGHT

$0 \quad$ No

$1 \quad$ Yes 
28) Violence (adolescent onset): includes aggravated assault and robbery, etc. VIOLAO

$\begin{array}{ll}0 & \text { No } \\ 1 & \text { Yes }\end{array}$

29) Is the youth sexually acting out? (e.g., solitary and interpersonal) SEXACTOUT $\begin{array}{ll}0 & \text { No } \\ 1 & \text { Yes }\end{array}$

30) Is there presence of sexual aggression (e.g., sexual touching and sexual assault)

$\begin{array}{ll}0 & \text { No } \\ 1 & \text { Yes }\end{array}$

SEXAGG

\section{SEVERITY}

31) Is there evidence of an increase in the level of severity of antisocial behaviours over time?

$\begin{array}{ll}0 & \text { No } \\ 1 & \text { Yes }\end{array}$

SEVER1

32) Is there evidence of an increase in the severity of non-aggressive antisocial behaviours over time?

SEVER2

$\begin{array}{ll}0 & \text { No } \\ 1 & \text { Yes }\end{array}$

33) Is there evidence of an increase in the severity from non-aggressive to aggressive behaviours over time?

$\begin{array}{ll}0 & \text { No } \\ 1 & \text { Yes }\end{array}$

SEVNAG2

34) Is there evidence of an increase in the severity of aggressive antisocial behaviours over time?

SEVAGG

$\begin{array}{ll}0 & \text { No } \\ 1 & \text { Yes }\end{array}$


35) Is there evidence of an increase in the severity of deviant sexual behaviours over time?

$\begin{array}{ll}0 & \text { No } \\ 1 & \text { Yes }\end{array}$

SEVSEXAG

\section{OTHER}

36) Does the youth display suicidal tendencies (includes ideations, gestures, selfmutilation, attempted suicide)?

SUICIDE

$0 \quad$ No

1 Yes

37) Index of problem behaviours: derived by adding the number of time the item is present in each of the following variables: \# 8-9, 14-21, 26-30, 36.

NUMBER MHS

\section{TREATMENT READINESS}

38) Treatment Readiness score

READSCORE

39) Treatment Readiness level

$(0-7=$ low, $8-15=$ moderate, $16-24=$ high $)$

READRANGE

0 Low

$1 \quad$ Moderate

2 High 